\title{
A time course analysis of the extracellular proteome of Aspergillus nidulans growing on sorghum stover
}

\author{
Sayali Saykhedkar ${ }^{1}$, Anamika Ray ${ }^{1}$, Patricia Ayoubi-Canaan ${ }^{1}$, Steven D Hartson ${ }^{1}$, Rolf Prade ${ }^{2}$ and Andrew J Mort ${ }^{\text {* }}$
}

\begin{abstract}
Background: Fungi are important players in the turnover of plant biomass because they produce a broad range of degradative enzymes. Aspergillus nidulans, a well-studied saprophyte and close homologue to industrially important species such as A. niger and A. oryzae, was selected for this study.

Results: A. nidulans was grown on sorghum stover under solid-state culture conditions for 1, 2, 3, 5, 7 and 14 days. Based on analysis of chitin content, A. nidulans grew to be 4-5\% of the total biomass in the culture after 2 days and then maintained a steady state of $4 \%$ of the total biomass for the next 12 days. A hyphal mat developed on the surface of the sorghum by day one and as seen by scanning electron microscopy the hyphae enmeshed the sorghum particles by day 5 . After 14 days hyphae had penetrated the entire sorghum slurry. Analysis (1-D PAGE LC-MS/MS) of the secretome of $A$. nidulans, and analysis of the breakdown products from the sorghum stover showed a wide range of enzymes secreted. A total of 294 extracellular proteins were identified with hemicellulases, cellulases, polygalacturonases, chitinases, esterases and lipases predominating the secretome. Time course analysis revealed a total of 196, 166, 172 and 182 proteins on day 1, 3, 7 and 14 respectively. The fungus used $20 \%$ of the xylan and cellulose by day 7 and $30 \%$ by day 14 . Cellobiose dehydrogenase, feruloyl esterases, and CAZy family 61 endoglucanases, all of which are thought to reduce the recalcitrance of biomass to hydrolysis, were found in high abundance.

Conclusions: Our results show that A. nidulans secretes a wide array of enzymes to degrade the major polysaccharides and lipids (but probably not lignin) by 1 day of growth on sorghum. The data suggests simultaneous breakdown of hemicellulose, cellulose and pectin. Despite secretion of most of the enzymes on day 1, changes in the relative abundances of enzymes over the time course indicates that the set of enzymes secreted is tailored to the specific substrates available. Our findings reveal that A. nidulans is capable of degrading the major polysaccharides in sorghum without any chemical pre-treatment.
\end{abstract}

Keywords: Cellulose, Biofuels, Lignocellulosic biocoversion, A. nidulans, Sorghum, Enzymatic hydrolysis, Proteome

\section{Introduction}

Lignocellulose, a major structural component of woody and non-woody plants, is abundant in nature and has a potential for bioconversion [1]. Lignocellulosic feedstocks like sorghum stover can contribute to abundant fermentable sugars after enzymatic treatment because $60 \%$ of its dry weight is cellulose and hemicelluloses [2]. Further it is drought tolerant, noninvasive, grows robustly, has low water requirement and a commercially

\footnotetext{
* Correspondence: andrew.mort@okstate.edu

${ }^{1}$ Department of Biochemistry and Molecular Biology, Oklahoma State University, Stillwater, OK 74078, USA

Full list of author information is available at the end of the article
}

viable annual crop producing up to 56 metric tons of dry biomass per hectare in the USA [3].

The major challenge imposed by plant cell walls to enzymatic hydrolysis is recalcitrance due to the complexity of the network of lignin, hemicelluloses and cellulose and the crystalinity of cellulose. Different processes including pretreatment with dilute acids, hot water, ammonia fiber explosion and treatment with $\mathrm{FeCl}_{3}$ have been tested to overcome this challenge [4-7]. The drawbacks of these pretreatments are accumulation of inhibitory compounds, use of harsh chemicals, hence the expense of the equipment, and lack of reaction specificity $[8,9]$.

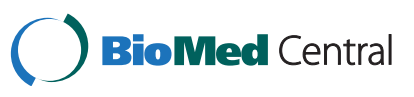


Fungi achieve lignocellulosic conversion under mild conditions, albeit rather slowly. Fungi are known to secrete hydrolytic enzymes that are responsible for polysaccharide degradation, but also must produce ligninolytic systems and enzymes to decrease the crystalinity of cellulose [1,10-12]. Here we present a description of the enzymes secreted by $A$. nidulans to support its growth on powdered sorghum stover. A. nidulans is a model saprophytic fungus, with a sequenced and annotated genome [13-15]. It is also a well-known producer of plant cell wall degrading enzymes [16,17]. Several proteomic studies on extracellular proteins from aspergillus species growing on various carbon sources have been reported [11,12,18-20]. However, no studies have been reported on growth of $A$. nidulans on sorghum to elucidate the comprehensive strategy of $A$. nidulans for degradation of plant cell walls.

In this study we grew $A$. nidulans on sorghum stover under solid state culture conditions to simulate the natural environment of the fungus. We aimed to identify all secreted enzymes involved in degradation of the sorghum over a time course of $1,2,3,5,7$ and 14 days and in $1 \%$ glucose grown cultures. Results from the study of growth, enzyme activities, quantification of breakdown products from the enzymes, and the nature of the remaining undigested sorghum should enhance our understanding of the plant cell wall degradation process and help us to devise ways to accelerate the process of lignocellulosic bioconversion using in vitro enzyme mixtures.

\section{Results}

To visualize the growth of $A$. nidulans in solid state sorghum cultures, $A$. nidulans samples grown on sorghum stover were sampled on 0,3 and 5 days after inoculation and analyzed by scanning electron microscopy (SEM) and transmission electron microscopy (TEM). The SEM image in Figure 1A shows uninoculated sorghum particles as a control. Figure 1B indicates dense growth of $A$. nidulans on sorghum stover on day 5 by SEM.
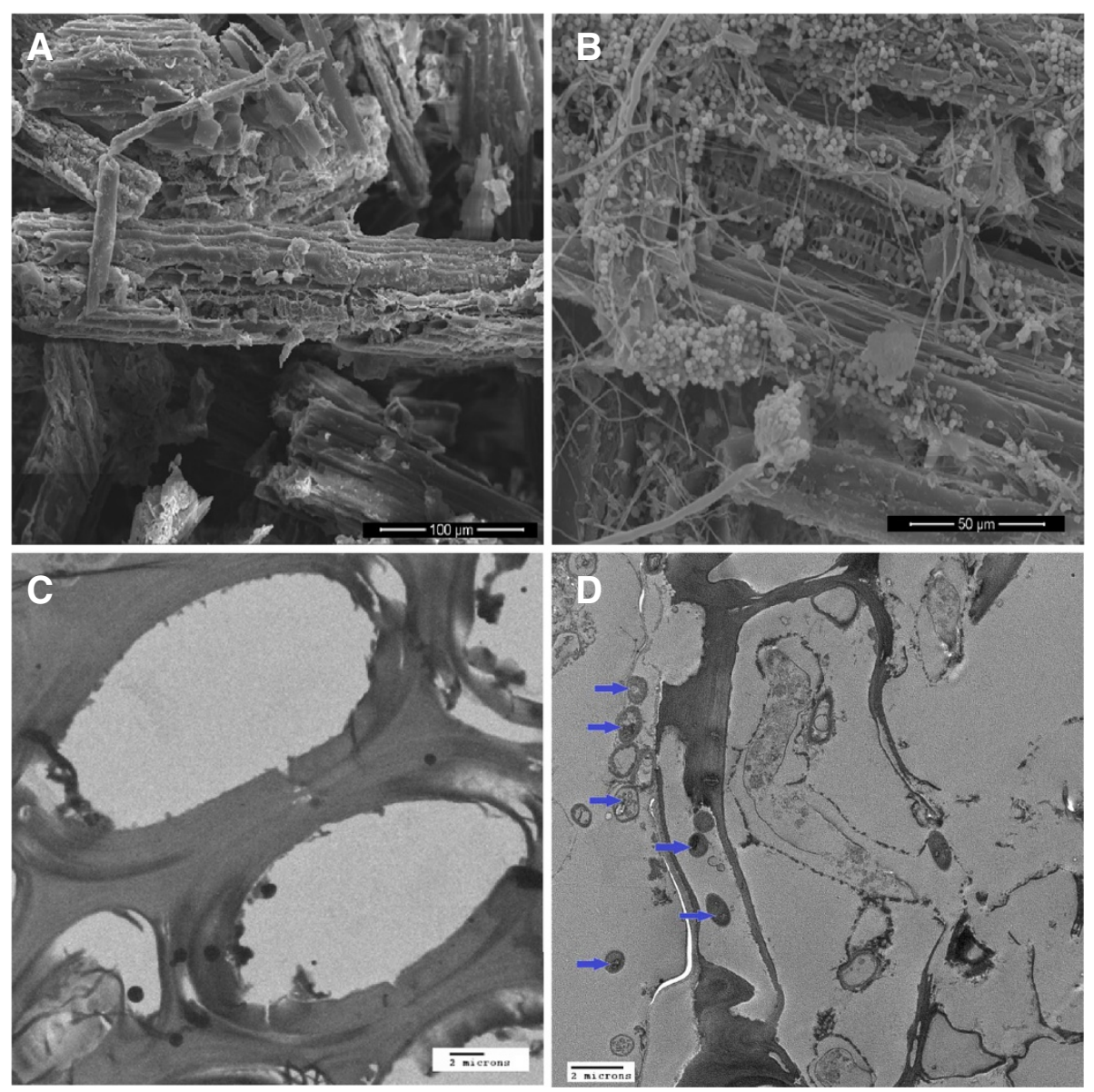

Figure 1 Growth of $\boldsymbol{A}$. nidulans on sorghum stover. A. Scanning electron micrograph (SEM) of sorghum particles without any fungal inoculation, B. Scanning electron micrograph of sorghum particles enmeshed with fungal mycelia on day 5 showing substantial growth of $A$. nidulans. C. Transmission electron micrograph of cross section of sorghum particles without any fungal inoculations. D. Cross section of sorghum particles showing presence of fungal particles inside sorghum cells. 


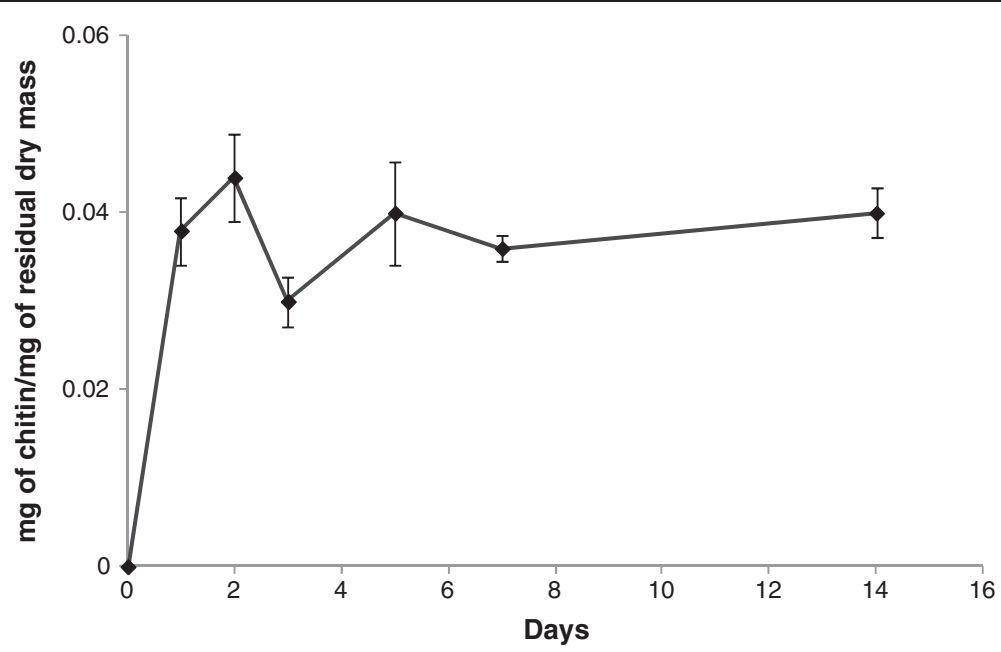

Figure 2 Growth of fungus on sorghum measured quantitatively by estimation of chitin. Determination of fungal biomass was done by establishing a conversion factor relating glucosamine to mycelial dry weight. Results are expressed as mg of cells/ mg of dry mass. Dry mass refers to total mass including fungal biomass and residual sorghum. Data represent mean \pm SE.

Figure $1 \mathrm{C}$ is a control depicting only sorghum cell walls imaged by TEM. Figure 1D depicts fungal cells surrounding and within the sorghum cells on day 5 by TEM. By day 1 we saw a mat of fungus covering the surface of the sorghum slurry. The mat appeared to be getting thicker and penetrated throughout the sorghum slurry by day 14 .

To quantitate the growth of A. nidulans in the solidstate cultures, the total chitin content of the cultures was measured. We selected this approach because fungal biomass is difficult to recover and separate from the sorghum particles as the fungal hyphae enmesh and bind tightly to the substrate [21]. Chitin is a long-chain polymer of N-acetyl glucosamine and a key constituent of the fungal cell walls. As no chitin-like materials occur in sorghum stover, determination of chitin content is a good measure of fungal growth. Results from the chitin estimation revealed that $A$. nidulans grew rapidly on day 1 reaching to $3.8 \%$ of the total dry biomass on the plate. After day 2 it reached a maximum (4.4\% of the total dry biomass) but decreased on day 3 and then became relatively constant for rest of the days (Figure 2).

Enzyme activities in the extracellular filtrate (ECF) varied during the growth of $A$. nidulans on the sorghum (Figure 3). Xylanases showed high activity $(0.98 \mathrm{U} / \mathrm{ml})$ on day 1 and the activity increased slowly over the next 6 days. Polygalacturonase activity was lower than xylanase activity on days 1 and $2(0.23$ and $0.59 \mathrm{U} / \mathrm{ml}$ respectively) with the polygalacturonase activity becoming constant subsequently. Cellulase activity, as measured using carboxymethylcelluose as substrate, reached a fairly constant level of around $0.27 \mathrm{U} / \mathrm{ml}$ after day 1 .

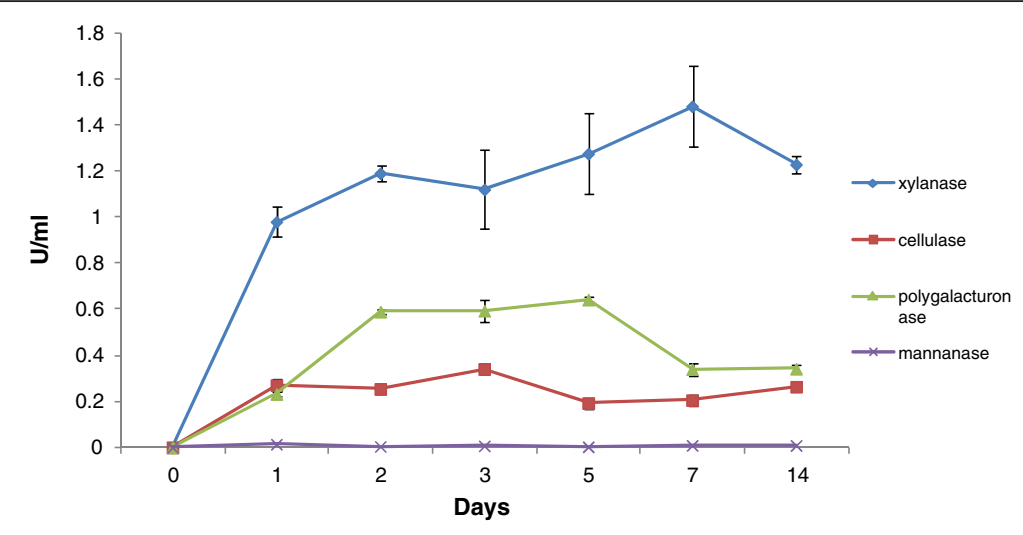

Figure 3 Estimation of enzyme activities. Levels of xylanase, cellulase, polygalacturonase and mannanase activities in A. nidulans grown on sorghum for 1, 2, 3, 5, 7 and 14 days. Enzyme activities were measured by the released reducing sugars as measured by the 3, 5-dinitrosalicylic acid (DNS) method and expressed as $\mathrm{U} / \mathrm{ml}$. One unit of enzyme activity was defined as the amount of enzyme releasing $1 \mu \mathrm{mol}$ of product per minute. Data represent mean \pm SE. 
Mannanase activity was not detectable by colorimetric methods. Capillary zone electrophoresis (CZE) analysis, of fluorescently labeled substrates revealed a range of hemicellulase, cellulase, pectinase and mannanase activities in the A. nidulans cultures (Data not shown). We did not detect any of the above polysaccharide degrading enzyme activities in ECF collected from glucose control.

The next logical step after determining the enzymatic activities was to identify the individual extracellular enzymes involved in degradation of the sorghum. The $A$. nidulans secretome was analyzed using 1D PAGE LCMS/MS. Spectrum counts were used to show the relative abundance of the proteins in extracellular filtrates.
Spectrum counts are the total number of tandem spectra assigned to each protein and are commonly used to determine relative protein abundances because previous studies have demonstrated a linear correlation between spectrum count and protein abundance in complex samples [22]. The results of the analysis of the secretome are presented in Tables 1, 2, 3, 4, 5, 6, 7, 8, 9 and 10 and additional file 1: Table S1. A total of 7 proteins were identified in the ECF of $1 \%$ glucose grown cultures. These proteins were a hypothetical protein (AN4575), thioredoxin reductase (AN8218), N-acetyl-6-hydroxytryptophan oxidase (AN0231), heat shock protein (AN5129), alkaline protease (AN5558), nucleoside

Table 1 Identified hemicellulose-degrading proteins and spectrum counts on 1, 3, 7, and 14 days

\begin{tabular}{|c|c|c|c|c|c|c|c|c|}
\hline \multirow[b]{2}{*}{ Accession number ${ }^{a}$} & \multirow[b]{2}{*}{ GH family $^{\mathrm{a}}$} & \multirow[b]{2}{*}{ Identified proteins $^{\mathrm{a}}$} & \multirow[b]{2}{*}{$\mathrm{MW}(\mathrm{kDa})^{\mathbf{b}}$} & \multirow[b]{2}{*}{ Day 1} & \multicolumn{2}{|c|}{ Spectrum count $^{c}$} & \multirow[b]{2}{*}{ Day 14} & \multirow[b]{2}{*}{ SignalP $\mathrm{P}^{\mathrm{d}}$} \\
\hline & & & & & Day 3 & Day 7 & & \\
\hline AN8401 & $\mathrm{GH} 3$ & Beta-1,4-xylosidase & 82 & 60 & 98 & 107 & 132 & Y \\
\hline AN2217 & $\mathrm{GH} 3$ & Beta 1,4-Xylosidase & 83 & 39 & 48 & 58 & 79 & Y \\
\hline AN2359 & $\mathrm{GH} 3$ & Beta-xylosidase & 87 & 53 & 115 & 57 & 0 & Y \\
\hline AN1818 & $\mathrm{GH} 10$ & Beta-1,4-endoxylanase & 34 & 101 & 142 & 576 & 720 & Y \\
\hline AN7401 & $\mathrm{GH} 10$ & Beta-1,4-endoxylanase & 38 & 0 & 4 & 11 & 31 & Y \\
\hline AN3613 & $\mathrm{GH} 11$ & Beta-1,4-endoxylanase A precursor & 24 & 188 & 174 & 194 & 140 & Y \\
\hline AN7152 & $\mathrm{GH} 27$ & Alpha-1,4-galactosidase & 69 & 67 & 138 & 124 & 121 & Y \\
\hline AN8138 & GH36 & Alpha-1,4-galactosidase & 82 & 0 & 0 & 27 & 24 & Y \\
\hline AN7117 & GH39 & Xylosidase & 50 & 0 & 9 & 13 & 12 & Y \\
\hline AN8007 & $\mathrm{GH} 43$ & Endoarabinase & 34 & 6 & 29 & 20 & 19 & Y \\
\hline AN2533 & $\mathrm{GH} 43$ & Alpha N-arabinofuranosidase & 36 & 0 & 13 & 10 & 7 & Y \\
\hline AN7781 & $\mathrm{GH} 43$ & Arabinosidase, putative & 38 & 32 & 74 & 52 & 60 & Y \\
\hline AN2534 & $\mathrm{GH} 43$ & Endoarabinase & 41 & 0 & 13 & 12 & 7 & Y \\
\hline AN10919 & $\mathrm{GH} 43$ & 1,4-endoxylanase D precursor & 42 & 2 & 39 & 50 & 48 & Y \\
\hline AN7313 & $\mathrm{GH} 43$ & Alpha L-arabinofuranosidase C & 52 & 0 & 5 & 0 & 0 & $Y$ \\
\hline AN7275 & $\mathrm{GH} 43$ & Putative xylosidase & 55 & 0 & 0 & 0 & 24 & $Y^{\mathrm{e}}$ \\
\hline AN8477 & $\mathrm{GH} 43$ & Xylosidase/arabinofuranosidase & 60 & 37 & 69 & 64 & 97 & $\mathrm{~N}^{f}$ \\
\hline AN5727 & GH53 & Beta-1,4-endogalactanase & 41 & 11 & 19 & 16 & 18 & Y \\
\hline AN1571 & GH54 & Alpha-arabinofuranosidase & 53 & 45 & 98 & 80 & 96 & Y \\
\hline AN2632 & GH62 & Arabinoxylan/arabinofuranohydrolase & 33 & 13 & 30 & 29 & 21 & Y \\
\hline AN7908 & GH62 & Arabinoxylan/arabinofuranohydrolase & 36 & 27 & 106 & 90 & 113 & Y \\
\hline AN9286 & GH67 & Alpha-glucuronidase & 94 & 14 & 17 & 69 & 104 & Y \\
\hline AN5061 & GH74 & Xyloglucanase & 88 & 0 & 0 & 0 & 7 & Y \\
\hline AN2060 & GH93 & Exo-arabinanase & 43 & 17 & 24 & 24 & 27 & Y \\
\hline AN6093 & CE1 & Acetyl xylan esterase & 34 & 0 & 9 & 6 & 4 & Y \\
\hline AN1320 & & Beta-1,4-endoxylanase B & 28 & 10 & 36 & 46 & 55 & Y \\
\hline AN6673 & & Alpha-fucosidase & 92 & - & - & 30 & 31 & Y \\
\hline AN9380 & & Bifunctional xylanase/ deacetylase & 26 & 10 & 6 & 9 & 14 & Y \\
\hline
\end{tabular}

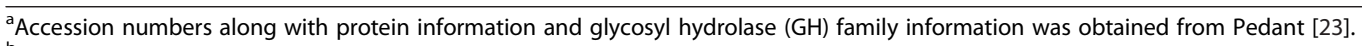

${ }^{\mathrm{b}}$ Hypothetical molecular weight of the proteins.

'Quantifying changes in protein abundance between samples from different time points was done using the spectral count method, yielding a semiquantitative analysis.

${ }^{\mathrm{d}}$ SignalP was used to predict secretion signals $[23,24]$.

esignalP as reported at [25].

${ }^{\mathrm{f}}$ Not found by SignalP (N-terminal may be incorrectly annotated, a novel signal peptide may be present, or the protein is normally intracellular but was released by autolysis). 
Table 2 Identified cellulose-degrading proteins and spectrum counts on 1, 3, 7, and 14 days

\begin{tabular}{|c|c|c|c|c|c|c|c|c|}
\hline \multirow[b]{2}{*}{ Accession number ${ }^{a}$} & \multirow[b]{2}{*}{ GH family $^{\mathrm{a}}$} & \multirow[b]{2}{*}{ Identified proteins ${ }^{a}$} & \multirow[b]{2}{*}{ MW $(\mathrm{kDa})^{\mathrm{b}}$} & \multicolumn{2}{|c|}{ Spectrum count $^{\mathrm{c}}$} & \multirow[b]{2}{*}{ Day 7} & \multirow[b]{2}{*}{ Day 14} & \multirow[b]{2}{*}{ SignalP ${ }^{\mathrm{d}}$} \\
\hline & & & & Day 1 & Day 3 & & & \\
\hline AN9183 & $\mathrm{GH} 1$ & Beta -1,4-glucosidase & 66 & 11 & 14 & 22 & 14 & Y \\
\hline AN2227 & $\mathrm{GH} 3$ & Beta-1,4-glucosidase & 92 & 9 & 0 & 0 & 0 & $\mathrm{~N}^{f}$ \\
\hline AN2828 & $\mathrm{GH} 3$ & Beta-1,4-glucosidase & 78 & 33 & 144 & 131 & 156 & $Y$ \\
\hline AN4102 & $\mathrm{GH} 3$ & Beta glucosidase & 92 & 78 & 222 & 204 & 215 & Y \\
\hline AN5976 & $\mathrm{GH} 3$ & Beta glucosidase & 89 & 53 & 105 & 22 & 0 & Y \\
\hline AN7396 & $\mathrm{GH} 3$ & Beta glucosidase & 84 & 0 & 116 & 107 & 59 & $Y$ \\
\hline AN1804 & $\mathrm{GH} 3$ & Beta-1,4-glucosidase & 68 & 4 & 4 & 49 & 31 & Y \\
\hline AN10482 & $\mathrm{GH} 3$ & Beta-1,4-glucosidase & 94 & 0 & 9 & 21 & 10 & $Y$ \\
\hline AN1285 & GH5 & Beta-1,4-endoglucanase & 36 & 21 & 49 & 38 & 42 & Y \\
\hline AN8068 & GH5 & Putative endoglucanase & 63 & 0 & 20 & 46 & 28 & Y \\
\hline AN9166 & GH5 & Cellulase family protein & 45 & 0 & 9 & 0 & 5 & Y \\
\hline AN1273 & GH6 & Cellobiohydrolase & 41 & 12 & 37 & 23 & 39 & Y \\
\hline AN5282 & $\mathrm{GH} 6$ & Cellobiohydrolase & 47 & 0 & 15 & 49 & 54 & Y \\
\hline AN0494 & $\mathrm{GH7}$ & Cellobiohydrolase & 56 & 15 & 33 & 58 & 80 & Y \\
\hline AN5176 & $\mathrm{GH7}$ & Cellobiohydrolase & 48 & 63 & 142 & 195 & 234 & $Y$ \\
\hline AN3418 & $\mathrm{GH7}$ & Beta-1,4-endoglucanase & 46 & 65 & 82 & 76 & 88 & Y \\
\hline AN2664 & $\mathrm{GH} 43$ & Beta-glucanase, putative & 55 & 0 & 0 & 0 & 7 & Y \\
\hline AN3046 & GH61 & Endoglucanase, putative & 32 & 44 & 0 & 0 & 0 & Y \\
\hline AN3860 & GH61 & Endoglucanase IV precursor & 26 & 5 & 0 & 14 & 17 & Y \\
\hline AN10419 & GH61 & Beta-1,4-endoglucanase & 29 & 0 & 10 & 10 & 16 & Y \\
\hline AN6428 & GH61 & Endoglucanase 4 & 24 & 2 & 0 & 5 & 7 & Y \\
\hline
\end{tabular}

${ }^{a}$ Accession numbers along with protein information and glycosyl hydrolase (GH) family information was obtained from Pedant [23].

${ }^{\mathrm{b}}$ Hypothetical molecular weight of the proteins.

'Quantifying changes in protein abundance between samples from different time points was done using the spectral count method, yielding a semiquantitative analysis.

${ }^{\mathrm{d} S i g n a l P}$ was used to predict secretion signals $[23,24]$.

eSignalP as reported at [25].

${ }^{f}$ Not found by SignalP ( $\mathrm{N}$-terminal may be incorrectly annotated, a novel signal peptide may be present, or the protein is normally intracellular but was released by autolysis).

diphosphate kinase (AN8216) and catalase B precursor (AN9339). We identified a total of 196, 166, 172 and 182 proteins on days $1,3,7$ and 14 respectively during the growth of $A$. nidulans on the sorghum stover. In the sorghum grown samples, eighty-nine proteins were present on all days. Eighty-proteins were exclusively secreted on day 1 , whereas only 7,5 and 19 proteins were unique to days 3,7 and 14 respectively. Results of LC-MS/MS studies on $A$. nidulans are described below for enzymes directed against different polymers or processes. Where possible the CAZy family affiliation for each enzyme has been noted.

\section{Hemicellulose degradation}

Hemicellulose is the second most abundant fraction (25$35 \%)$ of lignocellulosic biomass [20]. Hydrolysis of hemicelluloses into simple sugars requires multiple enzymes including beta-1,4-endoxylanase, beta-xylosidase, alphaglucuronidase, alpha-L-arabinofuranosidase and acetyl xylan esterase [26,27]. Beta-endoxylanases cleaves the backbone of xylan and beta-xylosidase releases the xylose units from xylobiose and xylooligomers. Removal of xylan side chains is catalyzed by acetyl xylan esterases, ferulic acid esterases, alpha-L-arabinofuranosidases and alpha-D-glucuronidases [28,29]. Xyloglucanactive beta-1, 4-endoglucanase and beta-1,4-glucosidase cleaves xyloglucan backbone and beta-1,4-endomannanase and beta1,4-mannosidase acts on (galacto-) mannan backbone $[28,30]$. Twenty-eight different hemicelluloses degrading enzymes were identified in our study (Table 1). A total of twenty A. nidulans ORFs have been assigned to GH3 family with three of them being beta-xylosidases [31]. We found all three of these beta-xylosidases (AN8401 AN2359, AN2217). Beta-xylosidases (AN8401 and AN2217) were present in abundance on day 1 and showed a steady increase in spectrum count until day 14. Another beta-xylosidase (AN2359) was present on day 1, 3 and 7 but not on day 14. AN7275, a putative GH43 family xylosidase, only appeared on day 14 . We found two of the potential three endoxylanses belonging to GH10 family (AN1818 and AN7401) and one out of the two belonging to GH11 family (AN3613). Beta-1,4- 
Table 3 Identified pectin-degrading proteins and spectrum counts on 1, 3, 7, and 14 days

\begin{tabular}{|c|c|c|c|c|c|c|c|c|}
\hline \multirow[b]{2}{*}{ Accession number ${ }^{a}$} & \multirow[b]{2}{*}{ GH family $^{\mathrm{a}}$} & \multirow[b]{2}{*}{ Identified proteins $\mathrm{s}^{\mathrm{a}}$} & \multirow[b]{2}{*}{ MW $(\mathrm{kDa})^{\mathrm{b}}$} & \multicolumn{3}{|c|}{ Spectrum count ${ }^{c}$} & \multirow[b]{2}{*}{ Day 14} & \multirow[b]{2}{*}{ SignalP } \\
\hline & & & & Day 1 & Day 3 & Day 7 & & \\
\hline AN2463 & $\mathrm{GH} 2$ & Beta-galactosidase & 115 & 0 & 0 & 50 & 96 & $N^{f}$ \\
\hline AN2395 & $\mathrm{GH} 2$ & Beta-galactosidase/mannosidase & 69 & 25 & 70 & 83 & 81 & Y \\
\hline AN8761 & $\mathrm{GH} 28$ & Exopolygalaturonase & 48 & 49 & 38 & 18 & 0 & Y \\
\hline AN8891 & $\mathrm{GH} 28$ & Exopolygalaturonase & 49 & 30 & 20 & 0 & 0 & Y \\
\hline AN10274 & $\mathrm{GH} 28$ & Exo-polygalacturonase, putative & 46 & 0 & 4 & 0 & 0 & Y \\
\hline AN0980 & $\mathrm{GH} 35$ & Beta-galactosidase & 109 & 2 & 14 & 8 & 25 & Y \\
\hline AN0756 & GH35 & Beta-galactosidase & 109 & 0 & 5 & 2 & 8 & Y \\
\hline AN7151 & $\mathrm{GH78}$ & Alpha-rhamnosidase & 100 & 4 & 14 & 64 & 83 & $\mathrm{~N}^{\mathrm{f}}$ \\
\hline AN7828 & GH88 & Unsaturated rhamnogalacturonan hydrolase & 44 & 11 & 0 & 0 & 0 & Y \\
\hline AN9383 & GH105 & Unsaturated rhamnogalacturonan hydrolase & 43 & 92 & 54 & 60 & 39 & $\mathrm{Y}$ \\
\hline AN0741 & PL1 & Pectate lyase precursor & 35 & 7 & 41 & 28 & 41 & Y \\
\hline AN2331 & PL1 & Pectin lyase A precursor & 41 & 17 & 0 & 0 & 0 & $Y$ \\
\hline AN2569 & PL1 & Pectin lyase A precursor & 39 & 32 & 29 & 47 & 31 & Y \\
\hline AN7646 & PL1 & Pectate lyase A & 35 & 4 & 3 & 19 & 18 & Y \\
\hline AN6106 & PL3 & Pectate lyase C & 26 & 6 & 22 & 20 & 23 & Y \\
\hline AN8453 & PL3 & Pectate lyase C & 28 & 10 & 0 & 5 & 3 & Y \\
\hline AN7135 & PL4 & Rhamnogalaturonan lyase & 56 & 13 & 71 & 71 & 80 & Y \\
\hline AN4139 & PL4 & Rhamnogalaturonan lyase & 117 & 6 & 15 & 3 & 5 & Y \\
\hline AN3390 & CE8 & Pectin methylesterase & 35 & 0 & 19 & 11 & 16 & Y \\
\hline AN4860 & CE8 & Pectin methylesterase & 42 & 27 & 3 & 0 & 0 & Y \\
\hline AN2528 & CE12 & Rhamnogalaturonan acetyl esterase & 26 & 4 & 0 & 16 & 16 & Y \\
\hline AN2537 & & Exopolygalacturonate lyase & 44 & 4 & 12 & 6 & 5 & Y \\
\hline
\end{tabular}

${ }^{\mathrm{a}}$ Accession numbers along with protein information and glycosyl hydrolase $(\mathrm{GH})$ family information was obtained from Pedant[23].

${ }^{b}$ Hypothetical molecular weight of the proteins.

'Quantifying changes in protein abundance between samples from different time points was done using the spectral count method, yielding a semiquantitative analysis.

${ }^{d}$ SignalP was used to predict secretion signals $[23,24]$.

eSignalP as reported at [25].

${ }^{f}$ Not found by SignalP ( $\mathrm{N}$-terminal may be incorrectly annotated, a novel signal peptide may be present, or the protein is normally intracellular but was released by autolysis).

endoxylanase (AN1818) showed a dramatic increase in spectrum count from 101 on day 1 to 720 on day 14 . AN3613 started with a high spectrum count on day 1 and then reached a plateau. AN7401 (which has a CBM) was present in lower abundance compared to the other xylanases. An alpha-1,4-galactosidase belonging to family GH27 and another belonging to GH36 (AN7152 and AN8138) were identified. AN7152 was found in high

Table 4 Identified starch degrading proteins and spectrum counts on 1, 3, 7, and 14 days

\begin{tabular}{|c|c|c|c|c|c|c|c|c|}
\hline \multirow[b]{2}{*}{ Accession number ${ }^{a}$} & \multirow[b]{2}{*}{ GH family ${ }^{a}$} & \multirow[b]{2}{*}{ Identified proteins $^{a}$} & \multirow[b]{2}{*}{$\mathrm{MW}(\mathrm{kDa})^{\mathrm{b}}$} & \multicolumn{2}{|c|}{ Spectrum count $^{c}$} & \multirow[b]{2}{*}{ Day 7} & \multirow[b]{2}{*}{ Day 14} & \multirow[b]{2}{*}{ SignalP } \\
\hline & & & & Day 1 & Day 3 & & & \\
\hline AN3388 & $\mathrm{GH} 13$ & Alpha amylase & 50 & 33 & 0 & 49 & 41 & Y \\
\hline AN3402 & $\mathrm{GH} 13$ & Alpha amylase & 69 & 11 & 0 & 0 & 0 & Y \\
\hline AN7402 & $\mathrm{GH} 15$ & Glucoamylase & 71 & 7 & 43 & 24 & 15 & $Y^{e}$ \\
\hline AN2017 & $\mathrm{GH} 31$ & Alpha-1,4-glucosidase & 110 & 5 & 12 & 5 & 6 & Y \\
\hline AN8953 & $\mathrm{GH} 31$ & Alpha-1,4-glucosidase B & 108 & 85 & 117 & 95 & 121 & $\mathrm{Y}$ \\
\hline AN0941 & $\mathrm{GH} 31$ & Alpha-1,4-glucosidase & 94 & 23 & 24 & 2 & 5 & $Y$ \\
\hline
\end{tabular}

${ }^{\mathrm{a}}$ Accession numbers along with protein information and glycosyl hydrolase (GH) family information was obtained from Pedant [23].

${ }^{\mathrm{b}}$ Hypothetical molecular weight of the proteins.

${ }^{\mathrm{C}}$ Quantifying changes in protein abundance between samples from different time points was done using the spectral count method, yielding a semiquantitative analysis.

${ }^{\mathrm{d}}$ SignalP was used to predict secretion signals $[23,24]$.

éSignalP as reported at [25]. 
Table 5 Identified fungal cell wall degradation/remodeling proteins and spectrum counts on 1, 3, 7, and 14 days

\begin{tabular}{|c|c|c|c|c|c|c|c|c|}
\hline \multirow[b]{2}{*}{ Accession number ${ }^{a}$} & \multirow[b]{2}{*}{ GH family $^{a}$} & \multirow[b]{2}{*}{ Identified proteins $\mathrm{s}^{\mathrm{a}}$} & \multirow[b]{2}{*}{$\mathrm{MW}(\mathrm{kDa})^{\mathrm{b}}$} & \multicolumn{3}{|c|}{ Spectrum count $^{c}$} & \multirow[b]{2}{*}{ Day 14} & \multirow[b]{2}{*}{ SignalP } \\
\hline & & & & Day 1 & Day 3 & Day 7 & & \\
\hline AN0933 & $\mathrm{GH} 16$ & Extracellular cell wall glucanase & 42 & 18 & 35 & 11 & 7 & Y \\
\hline AN0245 & $\mathrm{GH} 16$ & Beta-1,3(4)-endoglucanase, putative & 37 & 0 & 33 & 15 & 29 & Y \\
\hline AN6620 & $\mathrm{GH} 16$ & Beta-1,3(4)-endoglucanase, putative & 42 & 4 & 0 & 0 & 0 & Y \\
\hline AN6819 & $\mathrm{GH} 16$ & Endo-1,3 (4)-glucanase & 32 & 9 & 7 & 8 & 7 & Y \\
\hline AN7950 & $\mathrm{GH} 17$ & Cell wall beta-1,3-endoglucanase & 47 & 17 & 32 & 32 & 26 & Y \\
\hline$\overline{\text { AN4871 }}$ & $\mathrm{GH} 18$ & Protein similar to class $\vee$ chitinase $A$ & 44 & 5 & 224 & 277 & 317 & $\mathrm{~N}^{f}$ \\
\hline AN8241 & $\mathrm{GH} 18$ & Class III Chi A chitinase & 97 & 0 & 5 & 2 & 0 & Y \\
\hline AN1502 & $\mathrm{GH} 20$ & Protein similar to $\mathrm{N}$-acetylglucosaminidase & 68 & 11 & 101 & 124 & 176 & Y \\
\hline AN0779 & GH55 & Putative beta-1,3-exoglucanase & 84 & 0 & 19 & 19 & 15 & Y \\
\hline AN4825 & GH55 & Glucan 1,3-beta glucosidase precursor & 97 & 0 & 102 & 108 & 135 & Y \\
\hline AN9042 & GH71 & Putative alpha 1,3-glucanase & 69 & 0 & 51 & 55 & 60 & Y \\
\hline AN7657 & $\mathrm{GH} 72$ & 1,3-beta-glucanosyltransferase & 49 & 14 & 37 & 0 & 4 & Y \\
\hline AN0472 & GH81 & Putative beta-1,3-endoglucanase & 98 & 0 & 102 & 99 & 146 & Y \\
\hline AN9339 & & Catalase B precursor & 79 & 58 & 111 & 109 & 108 & Y \\
\hline AN4390 & & GPI-anchored cell wall organization protein Ecm33 & 41 & 4 & 7 & - & - & Y \\
\hline AN2385 & & GPI anchored beta-1,3(4)-endoglucanase, putative & 65 & 3 & - & - & - & Y \\
\hline
\end{tabular}

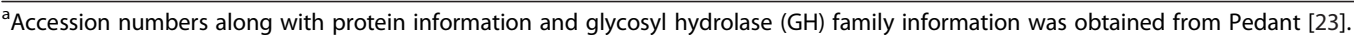

${ }^{b}$ Hypothetical molecular weight of the proteins.

'Quantifying changes in protein abundance between samples from different time points was done using the spectral count method, yielding a semiquantitative analysis.

${ }^{\mathrm{d}}$ SignalP was used to predict secretion signals $[23,24]$.

eSignalP as reported at [25].

${ }^{f} \mathrm{Not}$ found by SignalP ( $\mathrm{N}$-terminal may be incorrectly annotated, a novel signal peptide may be present, or the protein is normally intracellular but was released by autolysis).

abundance on all 4 days, whereas AN8138 was only secreted on day 7 and 14. Eight proteins (AN2533, AN7781, AN8007, AN2534, AN7275, AN8477, AN10919 and AN7313) belonging to family GH43 were identified. Out of these eight proteins, AN7275 and AN8477 do not have a signal peptide. AN7781 was secreted on all days. Its spectrum count increased more than twice from day 1 to day 3 and then it was constant on day 7 and 14. We identified an arabinosidase from family GH53 (AN1571), and two other arabinosidases (AN7908 and AN2632) belonging to family GH62. We also found one enzyme belonging to family GH53 (endogalactanase), one from GH67 (alpha-glucuronidase), and one from GH93 (exo-arabinase). Most of the hemicellulases were secreted on all days except for nine hemicellulases, which were absent on day 1 but secreted on all other days. One xyloglucanase (AN5061) appeared on day 14 only whereas galactosidase (AN8138) was found on only day 7 and 14 .

\section{Cellulose degradation}

The complete hydrolysis of cellulose requires random cleavage of internal bonds by endoglucanases, removal of cellobiose by cellobiohydrolases (exoglucanases), and

Table 6 Identified proteins involved in various plant cell wall modifications and spectrum counts on 1, 3, 7, and 14 days

\begin{tabular}{|c|c|c|c|c|c|c|c|c|}
\hline \multirow[b]{2}{*}{ Accession number ${ }^{a}$} & \multirow[b]{2}{*}{ GH family ${ }^{a}$} & \multirow[b]{2}{*}{ Identified proteins ${ }^{a}$} & \multirow[b]{2}{*}{ MW $(k D a)^{b}$} & \multicolumn{2}{|c|}{ Spectrum count $^{c}$} & \multirow[b]{2}{*}{ Day 7} & \multirow[b]{2}{*}{ Day 14} & \multirow[b]{2}{*}{ SignalP ${ }^{d}$} \\
\hline & & & & Day 1 & Day 3 & & & \\
\hline AN1772 & & Feruloyl esterase type B & 58 & 105 & 148 & 154 & 142 & $Y$ \\
\hline AN5267 & CE1 & Feruloyl esterase & 28 & 21 & 12 & 56 & 65 & $Y$ \\
\hline AN5311 & & Putative tyrosinase & 42 & 14 & 10 & 19 & 19 & $Y$ \\
\hline AN7230 & & Cellobiose dehydrogenase & 83 & 0 & 17 & 39 & 77 & $Y$ \\
\hline
\end{tabular}

${ }^{\mathrm{a}}$ Accession numbers along with protein information and glycosyl hydrolase (GH) family information was obtained from Pedant [23].

${ }^{b}$ Hypothetical molecular weight of the proteins.

${ }^{c}$ Quantifying changes in protein abundance between samples from different time points was done using the spectral count method, yielding a semiquantitative analysis.

${ }^{d}$ SignalP was used to predict secretion signals [23,24]. 
Table 7 Identified mannan degrading proteins and spectrum counts on 1, 3, 7, and 14 days

\begin{tabular}{|c|c|c|c|c|c|c|c|c|}
\hline \multirow[b]{2}{*}{ Accession number $^{a}$} & \multirow[b]{2}{*}{ GH family $^{a}$} & \multirow[b]{2}{*}{ Identified proteins $^{\mathrm{a}}$} & \multirow[b]{2}{*}{ MW $(\mathrm{kDa})^{\mathrm{b}}$} & \multicolumn{2}{|c|}{ Spectrum count $^{\mathrm{c}}$} & \multirow[b]{2}{*}{ Day 7} & \multirow[b]{2}{*}{ Day 14} & \multirow[b]{2}{*}{ SignalP } \\
\hline & & & & Day 1 & Day 3 & & & \\
\hline AN5361 & $\mathrm{GH} 2$ & Beta-1,4-mannosidase & 71 & 0 & 3 & 0 & 0 & Y \\
\hline AN9276 & GH5 & Beta-1,4-endomannanase & 42 & 0 & 5 & 8 & 15 & Y \\
\hline AN6427 & GH5 & Beta-1,4-endomannanase & 45 & 0 & 0 & 4 & 6 & $Y$ \\
\hline AN2936 & $\mathrm{GH} 38$ & Alpha-mannosidase & 124 & 0 & 4 & 38 & 72 & $\mathrm{~N}^{f}$ \\
\hline AN0787 & $\mathrm{GH} 47$ & Similar to class I alpha-mannosidase 1B & 56 & 10 & 48 & 53 & 58 & Y \\
\hline AN2325 & GH92 & Alpha-1,2-mannosidase & 82 & 0 & 11 & 15 & 7 & $Y$ \\
\hline AN1197 & $\mathrm{GH} 92$ & Alpha-1,2-mannosidase & 88 & 0 & 3 & 7 & 6 & Y \\
\hline
\end{tabular}

${ }^{\mathrm{a}}$ Accession numbers along with protein information and glycosyl hydrolase $(\mathrm{GH})$ family information was obtained from Pedant $[23,24]$.

${ }^{b}$ Hypothetical molecular weight of the proteins.

'Quantifying changes in protein abundance between samples from different time points was done using the spectral count method, yielding a semiquantitative analysis.

${ }^{\mathrm{d}}$ SignalP was used to predict secretion signals $[23,24]$.

e SignalP as reported at [25].

${ }^{f}$ Not found by SignalP (N-terminal may be incorrectly annotated, a novel signal peptide may be present, or the protein is normally intracellular but was released by autolysis).

release of glucose from cellobiose by beta-glucosidase [32-35]. Twenty-one different enzymes likely to be involved in cellulose degradation were identified in our cultures (Table 2). One beta-glucosidase (AN9183) belonging to family $\mathrm{GH} 1$ and seven beta-glucosidases belonging to family GH3 were detected. All of the family GH3 enzymes except AN2227 had recognizable signal peptide sequences. Beta-1,4-glucosidase (AN2828 and AN4102) showed high spectrum counts on all days, whereas AN7396 and AN5976 were absent on day 1 and day 14 respectively. Cellobiohydrolases are assigned to family GH6 and GH7. To date only family GH7 cellobiohydrolases have been characterized in A. nidulans [36] out of four predicted cellobiohydrolases belonging to family GH6 and GH7 from the A. nidulans genome sequence. We identified two cellobiohydrolases (AN1273 and AN5282) from family GH6 and two cellobiohydrolases (AN0494 and AN5176) belonging to family GH7. All showed a gradual increase in spectrum count from day 1 to day 14 . Notably cellobiohydrolase (AN5176) showed high spectrum count of 234 on day 14 as compared to other cellobiohydrolases, whereas AN5282 was absent on day 1 . We found one beta-1,4-endoglucanase (AN3418), from family GH7 and three betaendoglucanases belonging to family GH5. Endoglucanases (AN1285 and AN8068) showed relatively low spectrum counts compared to the beta-endoglucanases from family GH7. A cellulase family protein (AN9166) was only present on day 3 and 14 . We identified four beta-1,4-endoglucanases from family GH61 (AN10419, AN6428, AN3860 and AN3046) out of nine predicted ORFs for GH61 family proteins in the genome. Out of a total of twenty-one cellulases, seven enzymes were not secreted on day 1 whereas one putative endoglucanase AN2664 appeared only on day 14 .

\section{Pectin degradation}

Due to the complex structure of pectin an array of enzymes are needed for its degradation $[37,38]$. We identified twenty-two enzymes involved in pectin degradation (Table 3). The GH2 family contains betagalactosidase, beta-mannosidase and beta-glucuronidases. We found two GH2 family members (AN2935 and AN2463). Out of these two GH2 family members, AN2395 showed increased spectrum count across all days. GH28 family consists of endo- and exopolygalacturonases, rhamnogalacturonan hydrolases and xylogalacturonan hyrolases. Based on the A. nidulans genome nine ORFs have been assigned to this family. We identified three exopolygalacturonases (AN8761, AN8891, and AN10274) in the secretome. Out of three GH28 family exopolygalacturonases only AN8761 was

Table 8 Identified bacterial wall-degrading proteins and spectrum counts on 1, 3, 7, and 14 days

\begin{tabular}{|c|c|c|c|c|c|c|c|c|}
\hline \multirow[b]{2}{*}{ Accession number $^{a}$} & \multirow[b]{2}{*}{ GH family ${ }^{a}$} & \multirow[b]{2}{*}{ Identified proteins $^{a}$} & \multirow[b]{2}{*}{ MW $(\mathrm{kDa})^{\mathrm{b}}$} & \multicolumn{2}{|c|}{ Spectrum count } & \multirow[b]{2}{*}{ Day 7} & \multirow[b]{2}{*}{ Day 14} & \multirow[b]{2}{*}{ SignalP } \\
\hline & & & & Day 1 & Day 3 & & & \\
\hline AN6470 & $\mathrm{GH} 25$ & Putative N,O-diacetyl muramidase & 23 & 32 & 32 & 23 & 17 & Y \\
\hline AN8969 & $\mathrm{GH} 25$ & $\mathrm{~N}, \mathrm{O}$-diacetylmuramidase & 23 & 0 & 12 & 0 & 0 & $\mathrm{Y}$ \\
\hline
\end{tabular}

${ }^{\mathrm{a}}$ Accession numbers along with protein information and glycosyl hydrolase (GH) family information was obtained from Pedant [23].

${ }^{b}$ Hypothetical molecular weight of the proteins.

'Quantifying changes in protein abundance between samples from different time points was done using the spectral count method, yielding a semiquantitative analysis.

${ }^{\mathrm{d}}$ SignalP was used to predict secretion signals [23,24]. 
Table 9 Identified proteases and spectrum counts on 1, 3, 7, and 14 days

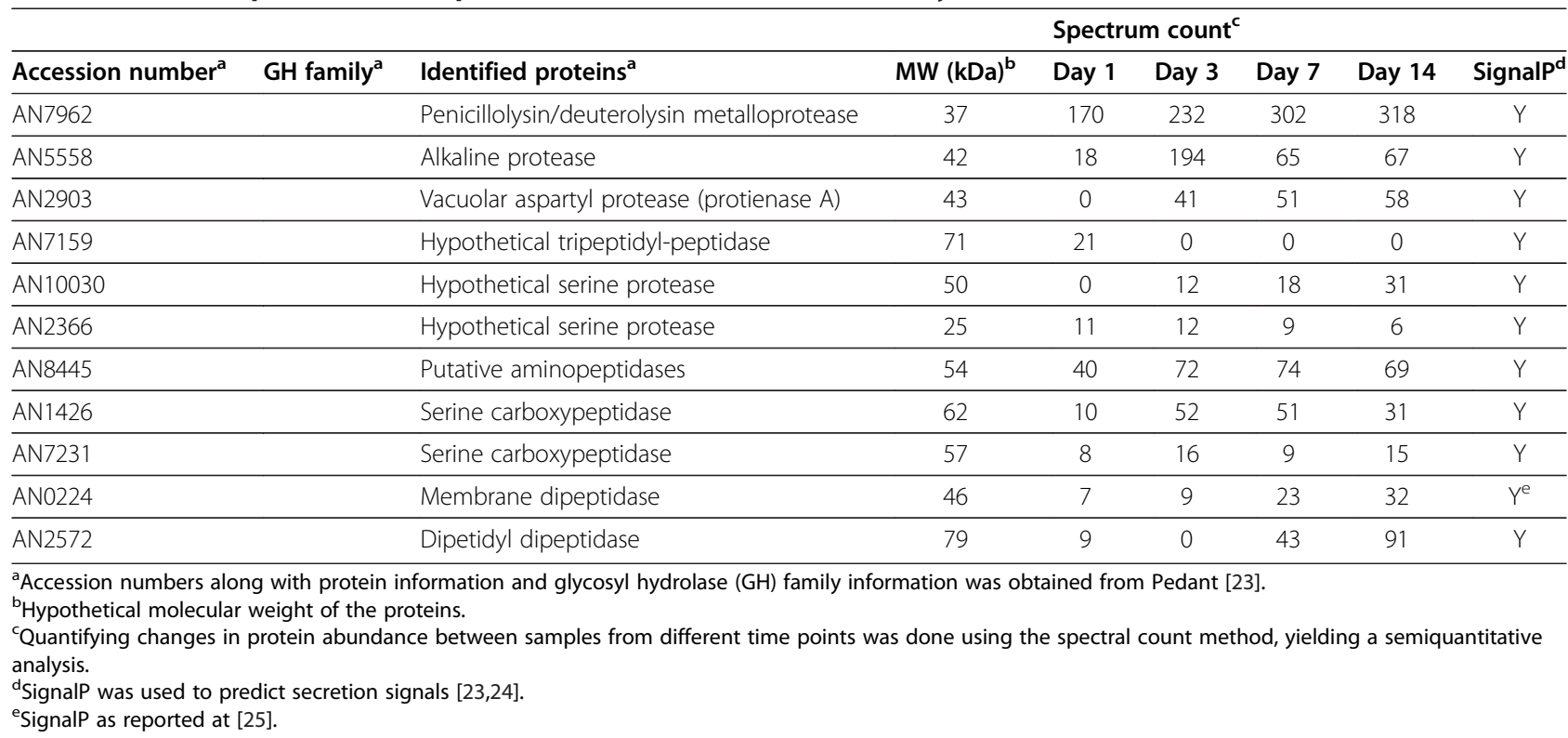

secreted with high abundance on all days. So far GH78 family contains alpha-L-rhamnosidase exclusively. Seven A. nidulans ORFs have been assigned to this family. We found one alpha-rhamnoside from GH78 (AN7151) and it showed a gradual increased in spectrum count across all the days. We identified two pectate and two pectin lyases from PL1 family and two from PL3 family. Four A. nidulans ORFs have been assigned to rhamnogalacturonan lyases from family PL4. We identified two members of PL4. Two unsaturated rhamnogalacturonan hydrolases (AN7828 and AN9383), two pectin methylesterases (AN4860 and
AN3390), and one rhamnogalacturonan acetylesterase (AN2528) were also identified. With the exception of members from GH2, GH78, GH105 and PL4, the pectinases were expressed at higher levels only in the early growth stages.

\section{Starch degradation}

Ten $A$. nidulans ORFs have been assigned to family GH31. We identified only three alpha-1,4-glucosidases from family GH31, two alpha-amylases from family GH13 and one amylase from family GH15 (Table 4).

Table 10 Identified esterases and lipases and spectrum counts on 1, 3, 7, and 14 days

\begin{tabular}{|c|c|c|c|c|c|c|c|c|}
\hline \multirow[b]{2}{*}{ Accession number $^{a}$} & \multirow[b]{2}{*}{ GH family $^{a}$} & \multirow[b]{2}{*}{ Identified proteins $^{\mathrm{a}}$} & \multirow[b]{2}{*}{$M W(k D a)^{b}$} & \multicolumn{3}{|c|}{ Spectrum count $^{c}$} & \multirow[b]{2}{*}{ Day 14} & \multirow[b]{2}{*}{ SignalP } \\
\hline & & & & Day 1 & Day 3 & Day 7 & & \\
\hline AN5309 & CE5 & Putative cutinase & 22 & 17 & 15 & 39 & 48 & Y \\
\hline AN7541 & CE5 & Cutinase, putative & 26 & 23 & 0 & 0 & 0 & Y \\
\hline AN2834 & CE12 & Esterase, putative & 27 & 6 & 0 & 0 & 0 & Y \\
\hline AN6422 & CE16 & Cellulose-binding GDSL Lipase/Acylhydrolase & 33 & 0 & 4 & 10 & 9 & Y \\
\hline AN5321 & & Extracellular lipase putative & 62 & 75 & 103 & 71 & 50 & Y \\
\hline AN9287 & & GDSL lipase/acylhydrolase & 47 & 23 & 52 & 49 & 50 & Y \\
\hline AN7691 & & Phosphoesterase superfamily protein & 50 & 23 & 55 & 44 & 13 & Y \\
\hline AN1792 & & GDSL lipase/acylhydrolase & 38 & 16 & 54 & 35 & 37 & Y \\
\hline AN8046 & & Putative extracellular lipase & 31 & 11 & 48 & 44 & 47 & Y \\
\hline AN1433 & & Putative triacylglycerol lipase & 60 & 24 & 16 & 6 & 0 & Y \\
\hline AN1799 & & Putative lipase & 48 & 0 & 0 & 13 & 39 & Y \\
\hline AN7046 & & Similar to triacylglycerol lipase & 25 & 3 & 0 & 0 & 0 & $Y$ \\
\hline AN9361 & & Lipase & 63 & 5 & - & - & - & $Y$ \\
\hline
\end{tabular}

${ }^{\mathrm{a} A c c e s s i o n}$ numbers along with protein information and glycosyl hydrolase (GH) family information was obtained from Pedant [23].

${ }^{\mathrm{b}}$ Hypothetical molecular weight of the proteins.

'Quantifying changes in protein abundance between samples from different time points was done using the spectral count method, yielding a semiquantitative analysis.

${ }^{\mathrm{d}}$ SignalP was used to predict secretion signals $[23,24]$. 


\section{Fungal cell wall remodeling enzymes}

Sixteen enzymes, including chitinases and beta-1,3endoglucanases involved in fungal cell wall modification/ degradation were identified (Table 5). Though chitinases and beta-1,3-endoglucanases were present on day 1 , the spectrum count of most of them increased notably on day 3 .

\section{Enzymes involved in various plant cell wall modifications}

Table 6 reports four enzymes, two feruloyl esterases, a cellobiose dehydrogenase, and a tyrosinase potentially involved in modification of lignin and other phenolics. The cellobiose dehydrogenase may also be involved in modification of cellulose.

\section{Mannan and bacterial cell wall degrading enzymes}

Table 7 and Table 8 show seven mannan degrading enzymes and two bacterial cell wall degrading enzymes respectively.

\section{Proteases}

Table 9 lists eleven fungal extracellular proteases, the production of which increased over time. They included one metallopreotease (AN7962) one alkaline protease, one aspartyl protease and two hypothetical serine proteases, two serine carboxypeptidases (AN1226, AN2237, AN7121), two putative aminopeptidase, an alkaline protease (AN5558), a putative dipeptidyl aminopeptidase (AN6438), and a membrane peptidase (AN7159). Table 10 show thirteen esterases and lipases secreted by A. nidulans. Out of these 12 esterases and lipases, seven were secreted with high abundance throughout the time course, whereas the rest of them were only present on one or two time points.

\section{Miscellaneous proteins}

Total 164 proteins were identified in this category including several hypothetical proteins (Additional file 1: Table S1).

The presence of high enzyme activities in the extracellular fluid of $A$. nidulans led us to quantify the solubilized breakdown products from the sorghum in the extracellular filtrate (ECF). Soluble polysaccharides and oligosaccharides present in ECF were estimated by gas chromatography after depolymerization by methanolysis and conversion of trimethylsilyl methyl glycosides. Between $0.01 \%$ and $0.23 \%$ of the total dry mass of the initial sorghum was soluble as each sugar type (Figure 4). The galacturonic acid and glucose content fell dramatically on day 1 and day 2 compared to the control suggesting that these already soluble sugars were readily converted into a form that could be taken up by the fungus. The amounts of arabinose and xylose containing soluble material increased compared to the control, reflecting digestion of the xylan by the enzymes and perhaps a lower ability to take up the solubilized products. The amount of mannose increased fairly consistently from day 1 to day 14. Rhamnose and galactose levels remained relatively constant. The amount of sugars at the different time points was probably a result of the dynamic balance between enzymatic breakdown of sorghum polysaccharides and uptake of sugars by fungus.

To find out how effective the fungus was at digesting the sorghum polysaccharides, we quantified the amount

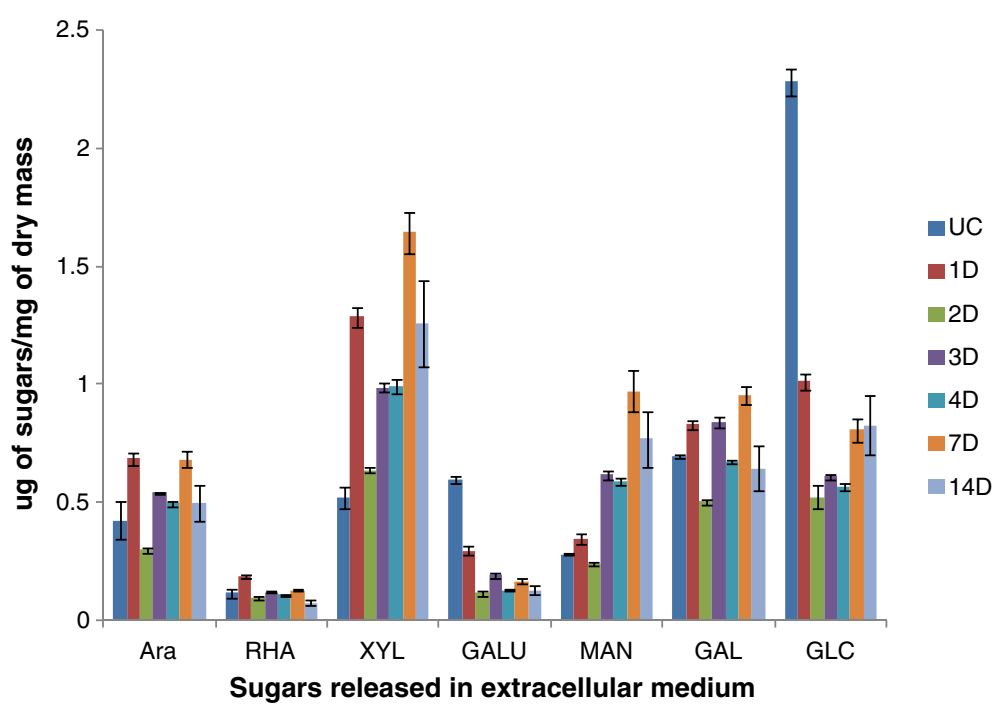

Figure 4 Estimation of soluble sugars in the extracellular medium of $\boldsymbol{A}$. nidulans grown on sorghum. This figure depicts breakdown products in the extracellular media after 1, 2, 3, 5, 7 and 14 days. The amounts of each sugar are shown as $\mu \mathrm{g}$ of sugars / mg of dry mass of sorghum. Soluble sugars in the un-inoculated control samples are designated as UC. Data represent mean \pm SE. 
of each sugar type remaining on the plate after various times of culture growth (Figure 5). Apart from a slight increase in glucose, which may have come from growth of the fungus or reflect experimental variability, the sorghum sugars decreased steadily. By day 7, 20\% of the measurable glucose and xylose had been consumed and by day $14,30 \%$ of these sugars had been utilized. The appearance of mannose and galactose, not present in the uninoculated sorghum, probably reflected the synthesis of fungal galactomannoproteins and mannans.

\section{Discussion}

A major goal of this study was to discover the enzymes A. nidulans secretes to digest sorghum stover while growing under conditions mimicking its natural habitat. These findings should help us to design a mixture of enzymes that can convert sorghum stover into readily fermentable sugars in vitro.

From the visual development of a thick fungal mat, the appearance of numerous fungal hyphae in electron microscopic images of the cultures (Figure 1), and the accumulation of chitin during the first two days of culture (Figure 2) we conclude that $A$. nidulans grows vigorously on a semi-solid sorghum slurry. However, although $A$. nidulans maintains a certain level of healthy biomass over a prolonged period, the actual fungal growth seems to reach a plateau after two days. From day 3 onwards we observed high levels of autolytic enzymes in the secretome indicating autolysis of the fungus. Class V chitinase, ChiB, AN4871, belonging to family GH18, N-acetylglucosaminidase, NagA, AN1502, belonging to family GH20, beta-1,3-endoglucanases AN4825 and AN0472, from family GH55 and GH81 respectively, the alkaline protease PrtA, AN5558, metallo- protease PepJ, AN7962, and dipeptidase AN2572 have all been shown to be associated with autolysis [39-42]. All were found to be highly induced from day 3 onwards (Table 5). On the other hand, Catalase B, an enzyme associated with growing and developing hyphae was found in high abundance throughout the time course [43]. Similarly enzymes associated with fungal cell wall synthesis and remodeling such as GPI-anchored cell wall organization protein Ecm33 (AN4390), and putative GPI anchored beta-1,3(4)-endoglucanase (AN2385) [44] were present in the secretome. Based on these findings, we propose that $A$. nidulans is maintaining growth throughout the time course but at the same time is recycling the older hyphae to support growth of hyphal tips and lateral branching. It is well established that lateral branching can be induced by fungal interaction with plants presumably leading to enhanced surface area and nutritional assimilation [45].

Powell et al. [2] studied the chemical composition of conventional grain sorghum, intermediate type sorghum and forage sorghum stover. They reported $31.3 \%$ cellulose content in grain type sorghum stover, $25.3 \%$ for intermediate sorghum stover, and $29.1 \%$ for forage type sorghum on a dry mass basis. The hemicellulose content was found to be $28.2 \%$ in grain sorghum stover, $21.7 \%$ in intermediate type sorghum stover, and $23.9 \%$ in forage type sorghum. The lignin content was between 7 to $7.3 \%$ for the three types of sorghum stover. In this study, the cellulose content was found to be $26.6 \%$ and the hemicellulose content was $22.3 \%$ of the total dry mass (Figure 5).

From the amount of xylanase and cellulase activities we found in the extracellular fluid collected from the culture on day 1 there should have been sufficient

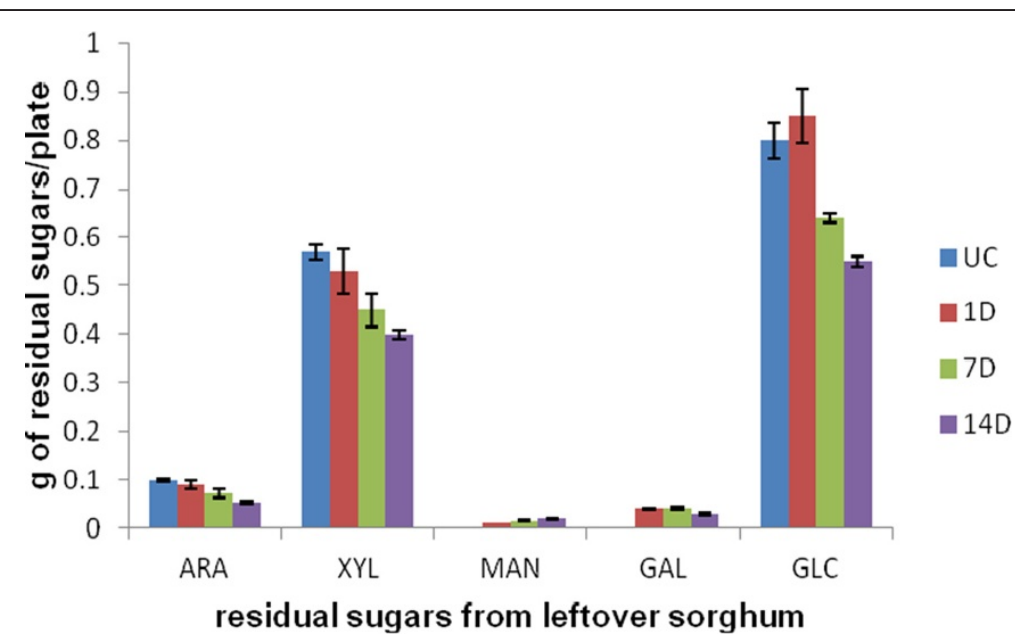

Figure 5 Estimation of residual sugars of sorghum collected from $A$. nidulans grown on sorghum. The sugars were estimated using Saeman hydrolysis. The results show the total sugar remaining from the initial $3 \mathrm{~g}$ of sorghum after 1, 7 and 14 days of growth of fungus on sorghum. The bars designated as UC show the amount of each sugar in $3 \mathrm{~g}$ of un-inoculated sorghum. Data represent mean \pm SE. 
enzyme activity to break down all the xylan and cellulose in the sorghum in less than a day. However the concentration of soluble sugars (break-down products from the enzymatic hydrolysis), in the extracellular fluid was low (less than $1 \mathrm{mM}$ ), and less than $5 \%$ of the total xylan had been digested and seemingly none of the cellulose. This emphasizes the well-known recalcitrance of plant biomass to enzymatic degradation and suggests that the fungus is growing under carbon limited conditions. However, over time, the fungus did appear to be able to digest all classes of cell wall polysaccharides present and it did continue to maintain a certain level of healthy biomass.

We were interested in determining if the fungus attacked the most easily digestible polymers first and then moved on to using the more recalcitrant ones. It has been suggested that fungi first degrade the pectin in plant cell walls to make the hemicelluloses and cellulose more accessible [46]. Sugars characteristic of pectin, i.e. rhamnose and galacturonic acid, were not detected in total hydrolysates of sorghum stover, although both of these sugars were found in the solubilized sugars rinsed from the cultures. This indicates the presence of a small amount of pectin in sorghum. Polygalacturonase activity was induced rapidly in the culture but xylanase and cellulase activity increased at the same time. Looking at the proteomics results one can deduce that almost all of the many enzymes involved in hemicellulose and cellulose degradation are induced in parallel. However in pectin degradation there is a steady decrease over time in exopolygalacturonases, one of the pectin methyl esterases, and one of the pectin lyases. In contrast there was a steep increase in other pectate lyases and rhamnogalacturonan hydrolases.

The recalcitrance of the sorghum or any other plant biomass to digestion is thought to arise from physical inaccessibility of the polymers to the enzymes designed to digest them. Two major factors are the incrustation of the polysaccharides with lignin and the crystalinity of the cellulose. We identified three classes of proteins which might play a key role in overcoming the recalcitrance of the sorghum to digestion.

There is strong evidence that some of the ferulic acids esterified to xylans crosslink to make diferulates which link xylans together thus making them less accessible to enzyme digestion. The ferulates can also be incorporated into lignin thus attaching xylan directly to lignin [47]. Hydrolysis of the ferulate ester bonds is expected to decrease the recalcitrance of biomass to enzymatic hydrolysis [48-50]. Two feruloyl esterases were secreted by A. nidulans in high abundance throughout the time course.

Another enzyme in our cultures which might play a role in overcoming recalcitrance of the sorghum to digestion is cellobiose dehydrogenase (CDH). CDHs oxidize cellobiose, or other reducing sugars, and transfer the electrons to $\mathrm{Fe}^{+++}$, quiniones, radicals, or oxygen to make hydrogen peroxide [51]. The combination of the resulting $\mathrm{Fe}^{++}$and hydrogen peroxide can lead to the generation of hydroxyl radical which will attack polysaccharides and lignin. At least three putative sequences for CDHs are present in the $A$. nidulans genome. We only detected one form. Interestingly $\mathrm{CDH}$ was not present on day 1 and then increased gradually showing a spectrum count of 17 on day 3 up to 77 on day 14 . No other studies have reported the secretion of cellobiose dehydrogenases by $A$. nidulans on solid state cultures. The presence of cellobiose dehydrogenase after day 3 may indicate its important role in the degradation of crosslinks between lignin, hemicelluloses and cellulose.

Whenever investigated, GH61 family endoglucanases lack measurable endoglucanase activity, but recently they have been reported to accelerate the hydrolysis of cellulose in cellulase preparations [52,53]. GH61 was initially described as an endoglucanase, but more recently has been shown to be members of the family are copper mono-oxygenases that catalyse cleavage of cellulose oxidatively, releasing cellodextrins $[53,54]$. Their active site contains a type II copper site, which, after being reduced to $\mathrm{Cu}^{+}$by a reductant such as ascorbate or gallate, is thought to activate oxygen which can then oxidize glycosidic linkages on the surface of crystalline cellulose. This generates new chain ends rendering the substrate far more prone to attack by the classical endoglucanases and cellobiohydrolases [52,53]. Cellobiose dehydrogenase appears to be able to mediate the reduction of the copper site [54]. Recent studies have shown that cellobiose dehydrogenase may enhance cellulose degradation by coupling the oxidation of cellobiose to the reductive activation of copper-dependent polysaccharide monooxygenases [53,54]. Four GH61 enzymes were found in our study.

Studies similar to ours were conducted by Schneider et al. [11] who grew $A$. nidulans and the mesophilic bacteria Pectobacterium carotovorum on leaf litter for 20 days, both individually and in co-culture, and identified the proteins secreted into the medium by $1-\mathrm{D}$ PAGE-LC-MS/MS. The aim of their study was to determine the relative contribution of the fungus and the bacterium to the decomposition. They reported a total of 90 proteins secreted by $A$. nidulans on leaf litter during the course of 20 days in comparison with the 294 proteins identified in our sorghum cultures. Seventy- two proteins were found to be common in both sorghum and leaf litter cultures, 59 proteins were exclusively found in the sorghum cultures and 13 were only identified in leaf litter cultures. The identities of the proteins in the two cultures are reported in Additional file 2: Table S2. More 
than half of the cellulases and xylanases were common to both cultures with two xylanases and four endoglucanases unique to leaf litter cultures. Only one pectinase out of 22 was unique to leaf litter. Interestingly enzymes involved in degradation of crosslinks between lignin, cellulose and hemicelluloses such as cellobiose dehydrogenase and feruloyl esterases were only identified in sorghum cultures. Only half the proteases and less than one third of cell wall remodeling enzymes were common to both the cultures. In another recent study, Couturier et al. [55] identified total 66 proteins in the secretome of $A$. nidulans grown on maize bran. Out of $19 \mathrm{GHs}$ identified in their study in A. nidulans secretome, seven hemicellulases belonging to family GH10, GH11, GH39, GH43, GH62 and GH93 and five beta-1,3-glucanases from the GH17, GH55 and GH81 families were identified. They could not detect any beta-1,4-endoglucanase or cellobiohydrolase or any enzyme activity on CMC [55]. The difference in growth and enzyme activities of A. nidulans on sorghum and on leaf litter may be attributed to different substrates compositions and growth conditions [12].

\section{Conclusions}

We have identified extracellular proteins secreted during the entire time course of cultivation of $A$. nidulans on sorghum stover. The aim was to learn the cocktail of enzymes we can devise to hydrolyze lignocellulosic biomass efficiently under mild conditions. In this study we identified a total of 294 proteins including cellulases, hemicellulases, pectinases, carbohydrate esterases, chitinases, and many proteins of unknown function. The enzymes such as feruloyl esterases, cellobiose dehydrogenase, and the family GH61 endoglucanases can be important in accelerating biomass conversion by reducing the recalcitrance of cellulose. Some of the hypothetical proteins we found may work as non-hydrolytic accessory proteins aiding hydrolytic enzymatic efficiency. Further work involving global/whole transcriptome studies of $A$. nidulans during its growth on sorghum may give insight into their function. Cloning and expression of the enzymes such as feruloyl esterases, cellobiose dehydrogenase and family 61 endoglucanases will let us test directly if they have beneficial effects.

\section{Materials and methods Growth conditions}

Aspergillus nidulans Strain A78 was obtained from the fungal genetic stock center (FGSC) [56]. $3 \mathrm{~g}$ of ground sorghum (variety mix of AtX2752/RtX2783 and AtX2752/ RtX430) was ground in a Thomas Wiley ${ }^{\circledR}$ Mini-Mill (Thomas Scientific, Swedesboro, NJ, USA) by passing through a 60-mesh screen. Fungal spores were counted using a hemacytometer (Spectrum Scientifics, Philadelphia, PA, USA) and adjusted to a million spores per milliliter in water. The ground sorghum was moistened with $6 \mathrm{ml}$ water in a petri plate and autoclaved for an hour at $121^{\circ} \mathrm{C}$. To these petri plates $15 \mathrm{ml}$ of minimal media $(\mathrm{pH} \mathrm{6.5}$; $95 \mathrm{ml}$ of water, $5 \mathrm{ml} 20 \mathrm{X}$ nitrate salts and $0.1 \mathrm{ml} \mathrm{1000X}$ trace elements) and $1 \mathrm{ml}$ of spore suspension containing $10^{6}$ spores was added. Then the petri plates were incubated at $37^{\circ} \mathrm{C}$ and $70 \%$ of relative humidity for $1,2,3,5,7$ and 14 days. Uninoculated sorghum stover incubated in same conditions as inoculated stover was used as control. All the chemicals used in this study were purchased from Sigma-Aldrich (St. Louis, MO, USA), unless otherwise stated. Fungus grown on borosilicate $3 \mathrm{~mm}$ solid glass beads (Aldrich, Milwaukee, WI) in 1\% glucose for 34 hours was used as a control for comparison of secretomes. A. nidulans cultured in $1 \%$ glucose for 34 hrs utilized only $1 / 4^{\text {th }}$ of the initial glucose and thus should not be undergoing starvation.

\section{Sample preparations for microscopy}

For scanning electron microscopy (SEM), fungal samples approximately, $5 \mathrm{~mm}$ squares, were cut from the plates and placed in the first fixative solution (2.5\% glutaraldehyde in $0.2 \mathrm{M}$ sodium phosphate, $\mathrm{pH} 7.2$ ) and incubated for $2 \mathrm{~h}$. The glutaraldehyde solution was removed and replaced with $0.2 \mathrm{M}$ sodium phosphate buffer, $\mathrm{pH} 7.2$ and samples were washed $3 \mathrm{X}$ for 20 min each. Post fixation was done in $1 \%$ osmium tetraoxide in $\mathrm{dH}_{2} \mathrm{O}$ for an hour. Dehydration was done with a series of ethanol solutions (50, 70, 90, 95,100,100,100\%), for 15 minutes each. Samples were critical point dried and mounted on aluminum stubs using silver paint adhesive followed by coating with gold/palladium. Samples were observed using an FEI quanta 600 electron microscopy (FEI, Hillsboro, OR, USA).

For transmission electron microscopy (TEM), the fixation was done as for the SEM samples. Post fixation was done in $1 \%$ osmium tetroxide $/ 1.5 \%$ potassium ferricyanide in $0.1 \%$ sodium cacodylate buffer for 1 hour. Using a series of ethanol solutions (as described in SEM protocol), samples were dehydrated for 15 minutes each. The dehydrated samples were washed $2 \mathrm{X}$ with $100 \%$ propylene oxide and then incubation overnight in propylene oxide/polyresin/bed 812 overnight (Polysciences Inc., Warrington, PA, USA) followed by immersion in polyresin/ bed 812 and polymerized at $60^{\circ} \mathrm{C}$. Samples were sectioned using a Leica EMCU 6 ultramicrotome (Midwest Lab Equipment, Iowa City, IA, USA). Sectioned samples were placed on nickel; carbon/formavar coated grids and stained with uranyl acetate and lead citrate and observed using a JEOL 2100 Transmission electron microscope (JEOL, Austin, TX, USA). 


\section{Estimation of fungal growth by chitin estimation}

The entire plate contents of $A$. nidulans cultures after day $1,2,3,5$, and 14 was freeze-dried and then mixed thoroughly. One mg samples were transferred to vials with teflon lined caps and hydrolyzed in $3 \mathrm{ml}$ of $6 \mathrm{~N}$ $\mathrm{HCl}$, at $100^{\circ} \mathrm{C}$ for $6 \mathrm{~h}$. The $\mathrm{HCl}$ was evaporated overnight in a speed-vac [57]. Once the extracts were dried, $10 \mu \mathrm{l}$ of $1 \mathrm{M}$ ammonium hydroxide was added to neutralize any residual $\mathrm{HCl}$. Then $10 \mu \mathrm{l}$ of 100 nanomoles methyl glucamine was added as an internal standard, followed by $100 \mu \mathrm{l}$ of $20 \mathrm{mg} / \mathrm{ml}$ potassium borohydride in DMSO and incubated at $40^{\circ} \mathrm{C}$ for $90 \mathrm{~min}$ to reduce hexosamines to hexosaminitols. After $90 \mathrm{~min}$ the reaction was stopped by adding $10 \mu \mathrm{l}$ glacial acetic acid, followed by addition of $20 \mu \mathrm{l}$ methyl imidazole and $200 \mu \mathrm{l}$ of acetic anhydride and incubated for $10 \mathrm{~min}$ at room temperature to acetylate the hexosaminitols [58,59]. The reaction was stopped by adding $500 \mu \mathrm{l}$ water and the alditol acetates were purified by adsorbing them to a C18 sep-pak and desorbing them with methylene chloride to remove the polyphoenols. The dichloromethane was then evaporated to dryness. $25 \mu \mathrm{l}$ of ethyl acetate was added to the dried sample, out of which, $1 \mu \mathrm{l}$ was injected into the gas chromatograph (Agilent, Santa Clara, CA, USA). A standard curve was prepared using known amounts of glucosamine ranging from 10 to $250 \mathrm{nmol}$. The glucosamine content of $1 \mathrm{mg}$ aliquots of dried A. nidulans grown in liquid media $(49.50 \mu \mathrm{g})$ was used as a conversion factor to estimate milligrams of fungus per milligram of dry mass.

\section{Estimation of enzyme activities by capillary zone electrophoresis (CZE) and dinitrosalicylic acid (DNS) assay} Extracellular extracts were collected by washing the whole petri plate contents with $5 \mathrm{ml}$ of autoclaved water and filtering the extract using Whatman no 1 filter paper. Enzyme activities were detected semi-quantitatively by CZE using 8-aminopyrene-1,3,6-trisulfonate (APTS) labeled substrates (xylohexose, cellopentose, arabinoheptaose, mannohexose) [60]. $1 \mu \mathrm{l}$ aliquots of extracellular extract and $2 \mu \mathrm{l}$ of respective APTS labeled substrates were added to $22 \mu \mathrm{l}$ of $50 \mathrm{mM}$ ammonium acetate buffer of optimum $\mathrm{pH}$ for the respective enzymes to make a total volume of $25 \mu$ l. Samples were incubated for $1 \mathrm{~h}$ at $37^{\circ} \mathrm{C}$ and the progress of enzymes was followed by CZE (Bio-Rad, Hercules, CA, USA).

The DNS assay, developed by Sumner and Graham [61] for determination of reducing sugar, was used for quantitative determination of enzyme activity. We used a DNS reagent composed of $0.75 \%$ di-nitrosalicylic acid, $0.5 \%$ phenol, $0.5 \%$ sodium metabisulfite, $1.4 \%$ sodium hydroxide, and $21 \%$ sodium potassium tartrate $[62,63]$. To $10 \mu \mathrm{l}$ of aliquot of extracellular extract, $20 \mu \mathrm{l}$ of $50 \mathrm{mM}$ ammonium buffer of optimum $\mathrm{pH}$ and $20 \mu \mathrm{l}$ of appropriate substrate $(1 \% \mathrm{~W} / \mathrm{V})$ prepared in water, were added. The reaction was carried out in a 96 well PCR plate (Corning, NY, USA) and allowed to incubate for 30 minutes at $37^{\circ} \mathrm{C}$. The reaction was terminated by addition of $40 \mu \mathrm{l}$ of DNS mixture to each well and the plate was heated at $100^{\circ} \mathrm{C}$ for $5 \mathrm{~min}$. We read the plate in a 96 well plate reader at 550 nanomoles (Tecan, San Jose, CA, USA). After subtracting substrate blanks from the reading enzyme activities were calculate from standard graphs.

\section{Estimation of solublized sugars in extracellular filtrate}

To identify and quantitate the breakdown products of the polysaccharides, oligosaccharides present in extracellular filtrate were estimated by gas chromatographic (GC) analysis of trimethylsilyl methyl glycosides. Methanolysis and derivatization were performed using the protocol of Chaplin [64] modified by Komalavilas and Mort [65]. A $25 \mu \mathrm{l}$ aliquot of sample and 100 nanomoles of inositol as an internal standard were dried in 1 dram glass vials in speed vac. $200 \mu \mathrm{l}$ of methanol $1.5 \mathrm{M}$ of HCI was added to each vial followed by addition of $100 \mu \mathrm{l}$ of methyl acetate and kept in a heating block at $80^{\circ} \mathrm{C}$ for minimum 3 hours. The vials were cooled, followed by addition of few drops of t-butanol and then evaporated under a stream of nitrogen at room temperatures. Butanol co-evaporates with the $\mathrm{HCl}$, helping to remove the $\mathrm{HCl}$ without degrading sugars. $25 \mu \mathrm{l}$ of 1:1:5 mixture of hexamethyldisilazane: trimethylchlrosilane: pyridine (TMS) was added to all samples. TMS in all the samples was evaporated using nitrogen gas. Dried samples were re-dissolved in $300 \mu \mathrm{l}$ of isooctane. $1 \mu \mathrm{l}$ of sample was injected in the gas chromatograph (Agilent, Santa Clara, CA, USA). Standards were made by taking aliquot of 100 nanomoles of each sugar standards and 100 nanomoles of inositol. From the integrator we calculated relative peak areas and used these to calculate how much of each sugar in sample. Area of sugar peak in sample/area of inositol peak in the sample/area of sugar peak in the standards/area of inositol in standards X $100=$ number of nanomoles in the sample.

\section{Liquid chromatography-tandem mass spectroscopy}

The fungal cultures grown on sorghum for day 1, 3, 7 and 14 and fungal culture grown in $1 \%$ glucose were washed with $5 \mathrm{ml}$ autoclaved water and the filtrates were collected. Concentration of total protein in these extracts was measured by Bradford assay. Small aliquots of the extracellular filtrates containing $50 \mathrm{ug}$ of total protein were run on SDS-PAGE. Gel bands were excised, reduced with Tris (2-carboxyethyl) phosphine), alkylated with 2-Iodoacetamide, and digested for $16 \mathrm{hrs}$ with $8 \mu \mathrm{g} / \mathrm{ml}$ trypsin using ammonium bicarbonate buffer. Peptides were extracted and analyzed by LC-MS/MS 
using an LTQ-Orbitrap XL hybrid mass spectrometer (Thermo Fisher Scientific, San Jose, CA, USA). For this analysis, an Eksigent spilt less LC pump (Eksigent, Dublin, CA, USA) was used to separate peptide populations on analytical C18 nano columns (Bruker-Michrom Inc., Auburn, CA, USA), with the column effluent being sprayed directly into a new objective pico view ion source. Using a "Big Three" MS/MS method, the Orbitrap analyzer collected an ultra-accurate $(\mathrm{R}=60,000)$ scan of intact peptides, whilst the LTQ ion trap simultaneously performed MS/MS fragmentation analysis of the each of three most abundant peptides eluting in that chromatographic fractions. The LC-MS/MS raw files were used for database searching via the software application Mascot (v2.2.2 from Matrix Science, Boston, MA, USA) against sequences from $A$. nidulans as well as against a sorghum database $[23,66]$. Searches were validated using Scaffold (Proteome Software Inc., Portland, OR, USA) and the Peptide Prophet algorithm [67]. Criteria for accepting protein identification, was only protein probability thresholds greater than $99 \%$ were accepted and at least two peptides needed to be identified, each with 95\% certainty. Protein candidates containing similar peptides were grouped to fulfill the principles of parsimony. Search results were also checked for false discoveries using reversed decoy sequence databases, and no decoy sequences were detected, thus bringing our false discovery rate to zero. Changes in protein expression between samples from different time points were examined using the spectral count method [68]. The complete peptide reports from the Scaffold results for samples taken from days 1, 3, 7, and 14 are given in Additional file 3: Table S3, Additional file 4: Table S4, Additional file 5: Table S5, and Additional file 6: Table S6 respectively. SignalP was used to predict secretion signals in the identified proteins $[69,70]$. Additional information for the presence of a signal peptide was obtained by accessing the following URL [25].

\section{Estimation of residual sorghum hydrolysates by saeman hydrolysis}

Saeman hydrolysis was done on the total biomass on the plates after 1, 7, and 14 days of fungal growth to estimate total sugars [30]. Three hundred mg samples of the thoroughly mixed freeze dried biomass from each petri plate were suspended in $3 \mathrm{ml}$ of $72 \%$ sulfuric acid. The samples were incubated at $30^{\circ} \mathrm{C}$ for $60 \mathrm{~min}$ with stirring every $5-10 \mathrm{~min}$ followed by dilution of sulfuric acid to $4 \%$ by adding $84 \mathrm{ml}$ of water and autoclaved for an hour at $121^{\circ} \mathrm{C} .2 \mathrm{ml}$ aliquot of each sample was neutralized with calcium carbonate to $\mathrm{pH} 5-6.25 \mu \mathrm{l}$ of sample was processed for methanolysis, trimethylsilylation, and gas liquid chromatography (GLC) analysis as described above.

\section{Additional Files}

Additional file 1: Table s1. Identified miscellaneous proteins and spectrum counts on 1, 3, 7, and 14 days.

Additional file 2: Table S2. Comparison of identified proteins in A. nidulans cultures from different carbon sources.

Additional file 3: Table S3. Protein report of A. nidulans grown on sorghum as carbon source on day1.

Additional file 4: Table S4. Protein report of A. nidulans grown on sorghum as carbon source on day3.

Additional file 5: Table S5. Protein report of A. nidulans grown on sorghum as carbon source on day7.

Additional file 6: Table S6. Protein report of A. nidulans grown on sorghum as carbon source on day14.

\section{Abbreviations}

1D-PAGE: One dimensional polyacrylamide electrophoresis; LC-MS/MS: Liquid chromatography-tandem mass spectroscopy; CAzY families: Carbohydrate active enzyme families; SEM: Scanning electron microscopy;

TEM: Transmission electron microscopy; CZE: Capillary zone electrophoresis; ORF: Open reading frame; GH: Glycosyl hydrolase; AN: Acession number; CBM: Carbohydrate binding module; PL: Pectin lyase; ECF: Extracellular filtrate; CDH: Cellobiose dehydrogenase; CMC: Carboxymethyl cellulose; FGSC: Fungal genetic stock center; APTS: 8-aminopyrene-1,3,6-trisulfonate; DNS: Dinitrosalicylic acid; PCR: Polymer chain reaction; GC: Gas

chromatography; TMS: Hexamethyldisilazane: trimethylchlrosilane: pyridine.

\section{Competing interest}

The authors declare that they have no competing interest.

\section{Acknowledgments}

This work was supported by USDA CSREES grant 2007-35504-18244, a grant from The Oklahoma Bioenergy Center, and the Oklahoma Agricultural Experiment Station. Microscopy work was performed in the OSU Microscopy Laboratory using electron microscopes purchased with grants from the National Science Foundation. We appreciate the technical assistance offered by the staff of the Laboratory. Mass spectrometry analyses were performed in the DNA/Protein Resource Facility at Oklahoma State University, using resources supported by the NSF MRI and EPSCoR programs (MRI/0722494). We appreciate the help and technical assistance offered by Janet Rogers in the DNA/Protein Resource Facility.

\section{Author details}

${ }^{1}$ Department of Biochemistry and Molecular Biology, Oklahoma State University, Stillwater, OK 74078, USA. ${ }^{2}$ Department of Microbiology and Molecular Genetics, Oklahoma State University, Stillwater, OK 74078, USA.

\section{Authors' contribution}

SS, AR, PAC, SDH, RP, and AJM conceived and designed various aspects of the experiments. SS and AR performed the experiments. SS, AR, PAC, SDH, $\mathrm{RP}$, and AJM al contributed to the analysis of the data, and the writing of the manuscript. All authors read and approved the final manuscript.

Received: 20 April 2012 Accepted: 26 July 2012

Published: 26 July 2012

\section{References}

1. Carmen S: Lignocellulosic residues: Biodegradation and bioconversion by fungi. Biotechnol Adv 2009, 27(2):185-194.

2. Powell J, Hons F, McBee G: Nutrient and carbohydrate partitioning in sorghum stover. Agron J 1991, 83:933-937.

3. Sierra R, Smith A, Cesar H, Mark T: Producing Fuels and Chemicals from Lignocellulosic. Chem Eng Prog 2008, 104(8):S10-S18. 
4. Lloyd TA, Wyman CE: Combined sugar yields for dilute sulfuric acid pretreatment of corn stover followed by enzymatic hydrolysis of the remaining solids. Bioresour Technol 2005, 96(18):1967-1977.

5. Teymouri F, Laureano-Pérez $L$, Alizadeh H, Dale B: Ammonia fiber explosion treatment of corn stover. Appl Biochem Biotechnol 2004, 115(1):951-963.

6. Kim S, Holtzapple MT: Effect of structural features on enzyme digestibility of corn stover. Bioresour Technol 2006, 97(4):583-591.

7. Liu L, Sun J, Li M, Wang S, Pei H, Zhang J: Enhanced enzymatic hydrolysis and structural features of corn stover by $\mathrm{FeCl}_{3}$ pretreatment. Bioresour Technol 2009, 100(23):5853-5858.

8. Shi J, Chinn MS, Sharma-Shivappa RR: Microbial pretreatment of cotton stalks by solid state cultivation of Phanerochaete chrysosporium. Bioresour Technol 2008, 99(14):6556-6564.

9. Zheng $\mathrm{R}$, Zhang $\mathrm{H}$, Zhao J, Lei $\mathrm{M}$, Huang $\mathrm{H}$ : Direct and simultaneous determination of representative byproducts in a lignocellulosic hydrolysate of corn stover via gas chromatography-mass spectrometry with a Deans switch. J Chromatogr A 2011, 5(31):5319-5327.

10. Szakacs G, Tengerdy RP: Production of cellulase and xylanase with selected filamentous fungi by solid substrate fermentation. In Enzymes for Pulp and Paper Processing, Volume 655.: American Chemical Society; 1996:175-182.

11. Schneider T, Gerrits B, Gassmann R, Schmid E, Gessner MO, Richter A, Battin $T$, Eberl $L$, Riedel K: Proteome analysis of fungal and bacterial involvement in leaf litter decomposition. Proteomics 2010, 10(9):1819-1830

12. Han M-J, Kim N-J, Lee S, Chang H: Extracellular proteome of Aspergillus terreus grown on different carbon sources. Curr Genet 2010, 56(4):369-382.

13. Aspergillus nidulans Project Information. http://www.broadinstitute.org/ annotation/fungi/aspergillus_nidulans_old/background.html.

14. Galagan JE, Calvo SE, Cuomo C, Ma L-J, Wortman JR, Batzoglou S, Lee S-I, Basturkmen M, Spevak CC, Clutterbuck J, et al: Sequencing of Aspergillus nidulans and comparative analysis with $A$. fumigatusand $A$. oryzae. Nature 2005, 438(7071):1105-1115

15. Wortman JR, Gilsenan JM, Joardar V, Deegan J, Clutterbuck J, Andersen MR, Archer D, Bencina M, Braus G, Coutinho P, et al: The 2008 update of the Aspergillus nidulans genome annotation: A community effort. Fungal Genetics and Biology 2009, 46(1, Supplement):S2-S13.

16. Bauer S, Vasu P, Persson S, Mort AJ, Somerville CR: Development and application of a suite of polysaccharide-degrading enzymes for analyzing plant cell walls. Proc Natl Acad Sci 2006, 103(30):11417-11422.

17. Coutinho PM, Andersen MR, Kolenova K, VanKuyk PA, Benoit I, Gruben BS, Trejo-Aguilar B, Visser H, Solingen P, Pakula T, et al: Post-genomic insights into the plant polysaccharide degradation potential of Aspergillus nidulans and comparison to Aspergillus niger and Aspergillus oryzae. Fungal Genetics and Biology 2009, 46(Supplement 1):S161-S169.

18. Medina ML, Haynes PA, Breci L, Francisco WA: Analysis of secreted proteins from Aspergillus flavus. Proteomics 2005, 5(12):3153-3161.

19. Oda K, Kakizono D, Yamada O, lefuji H, Akita O, Iwashita K: Proteomic analysis of extracellular proteins from Aspergillus oryzae grown under submerged and solid-state culture conditions. App/ Environ Microbiol 2006, 72(5):3448-3457.

20. Adav SS, Li AA, Manavalan A, Punt P, Sze SK: Quantitative iTRAQ Secretome Analysis of Aspergillus niger Reveals Novel Hydrolytic Enzymes. Journal of Proteome Research 2010, 9(8):3932-3940.

21. Suraini Abd-Aziz GSH, Mohd Ali H, Mohamed Ismail Abdul K, Noraini S: Indirect method for quantification of cell biomass during solid-state fermentation of palm kernel cake based on protein content. Asian Journal of Scientific Research 2008, 1(4385-393):385-393.

22. Zhou JY, Schepmoes AA, Zhang X, Moore RJ, Monroe ME, Lee JH, Camp DG, Smith RD, Qian WJ: Improved LC-MS/MS spectral counting statistics by recovering low-scoring spectra matched to confidently identified peptide sequences. J Proteome Res 2010, 9(11):5698-5704.

23. Pedant Database. http://pedant.gsf.de.

24. Walter MC, Rattei T, Arnold R, Guldener U, Munsterkotter M, Nenova K, Kastenmuller G, Tischler P, Wolling A, Volz A, et al: PEDANT covers all complete RefSeq genomes. Nucleic Acids Res 2009, 37(Database issue):21.

25. Aspergillus genome database. http://www.aspergillusgenome.org

26. Biely P: Microbial xylanolytic systems. Trends Biotechnol 1985 3(11):286-290
27. Coughlan MP, Hazlewood GP: beta-1,4-D-xylan-degrading enzyme systems: biochemistry, molecular biology and applications. Biotechnol Appl Biochem 1993, 17(Pt 3):259-289.

28. Javier PFI, Óscar G, Sanz-Aparicio J, Díaz P: Xylanases: Molecular properties and applications industrial enzymes. In In. Edited by Polaina J, MacCabe AP.: Springer Netherlands; 2007:65-82

29. de Vries RP, Visser J: Aspergillus enzymes involved in degradation of plant cell wall polysaccharides. Microbiol Mol Biol Rev 2001, 65(4):497-522.

30. Saeman JF, Bubl JL, Harris EE: Quantitative saccharification of wood and cellulose. Ind Eng Chem Anal Ed 1945, 17(1):35-37.

31. de Vries RP, van Grieken C, vanKuyk PA, Wösten HAB: The value of genome sequences in the rapid Identification of novel genes encoding specific plant cell wall degrading enzymes. Current Genomics 2005, 6(3):157-187.

32. Goyal A, Ghosh B, Eveleigh D: Characteristics of fungal cellulases. Bioresour Technol 1991, 36(1):37-50.

33. Rabinovich ML, Bolobova AV, Vasil'chenko LG: Fungal decomposition of natural aromatic structures and xenobiotics: A Review. Appl Biochem Microbiol 2004, 40(1):1-17.

34. Rabinovich ML, Melnick MS, Bolobova AV: The structure and mechanism of action of cellulolytic enzymes. Biochem Mosc 2002, 67(8):850-871.

35. Lynd LR, Cushman JH, NICHOLS RJ, WYMAN CE: Fuel ethanol from cellulosic biomass. Science 1991, 251(4999):1318-1323.

36. Bagga PS, Sandhu DK, Sharma S: Purification and characterization of cellulolytic enzymes produced by Aspergillus nidulans. J Appl Microbiol 1990, 68(1):61-68.

37. Martens-Uzunova ES, Schaap PJ: Assessment of the pectin degrading enzyme network of Aspergillus niger by functional genomics. Fungal Genetics and Biology 2009, 46(1, Supplement):S170-S179.

38. van den Brink J, de Vries RP: Fungal enzyme sets for plant polysaccharide degradation. Appl Microbiol Biotechnol 2011, 91(6):1477-1492.

39. Emri T, Molnár Z, Szilágyi M, Pócsi I: Regulation of autolysis in Aspergillus nidulans. Appl Biochem Biotechnol 2008, 151(2):211-220.

40. Jaques AK, Fukamizo T, Hall D, Barton RC, Escott GM, Parkinson T, Hitchcock CA, Adams DJ: Disruption of the gene encoding the ChiB1 chitinase of Aspergillus fumigatus and characterization of a recombinant gene product. Microbiology 2003, 149(10):2931-2939.

41. Yamazaki H, Yamazaki D, Takaya N, Takagi M, Ohta A, Horiuchi H: A chitinase gene, chiB, involved in the autolytic process of Aspergillus nidulans. Curr Genet 2007, 51(2):89-98.

42. Shin KS, Kwon NJ, Kim YH, Park HS, Kwon GS, Yu JH: Differential roles of the ChiB chitinase in autolysis and cell death of Aspergillus nidulans. Eukaryot Cell 2009, 8(5):738-746

43. Kawasaki L, Wysong D, Diamond R, Aguirre J: Two divergent catalase genes are differentially regulated during Aspergillus nidulans development and oxidative stress. J Bacteriol 1997, 179(10):3284-3292.

44. de Groot PWJ, Brandt BW, Horiuchi H, Ram AFJ, de Koster CG, Klis FM: Comprehensive genomic analysis of cell wall genes in Aspergillus nidulans. Fungal Genetics and Biology 2009, 46(1, Supplement):S72-S81.

45. Harris SD: Branching of fungal hyphae: regulation, mechanisms and comparison with other branching systems. Mycologia 2008, 100(6):823-832.

46. Karr AL, Albersheim P: Polysaccharide-degrading enzymes are unable to attack plant cell walls without Prior Action by a "Wall-modifying Enzyme". Plant Physiol 1970, 46(1):69-80.

47. Hatfield RD, Ralph J, Grabber JH: Cell wall cross-linking by ferulates and diferulates in grasses. J Sci Food Agric 1999, 79(3):403-407.

48. Koseki T, Hori A, Seki S, Murayama T, Shiono Y: Characterization of two distinct feruloyl esterases, AoFaeB and AoFaeC, from Aspergillus oryzae. Appl Microbiol Biotechnol 2009, 83(4):689-696.

49. Koseki T, Fushinobu S, Ardiansyah A, Shirakawa H, Komai M: Occurrence, properties, and applications of feruloyl esterases. Appl Microbiol Biotechnol 2009, 84(5):803-810.

50. Benoit I, Danchin E, Bleichrodt R-J, de Vries R: Biotechnological applications and potential of fungal feruloyl esterases based on prevalence, classification and biochemical diversity. Biotechnol Lett 2008, 30(3):387-396

51. Henriksson G, Johansson G, Pettersson G: A critical review of cellobiose dehydrogenases. J Biotechnol 2000, 78(2):93-113.

52. Harris PV, Welner D, McFarland KC, Re E, Navarro Poulsen J-C, Brown K, Salbo $R$, Ding $H$, Vlasenko $E$, Merino $S$, et al: Stimulation of lignocellulosic 
biomass hydrolysis by proteins of glycoside hydrolase family 61 : Structure and function of a large, enigmatic family. Biochemistry 2010, 49(15):3305-3316.

53. Quinlan RJ, Sweeney MD, Lo Leggio L, Otten H, Poulsen J-CN, Johansen KS, Krogh KBRM, Jørgensen Cl, Tovborg M, Anthonsen A, et al: Insights into the oxidative degradation of cellulose by a copper metalloenzyme that exploits biomass components. Proc Natl Acad Sci 2011, 108(37):15079-15084.

54. Langston JA, Shaghasi T, Abbate E, Xu F, Vlasenko E, Sweeney MD: Oxidoreductive cellulose depolymerization by the enzymes cellobiose dehydrogenase and glycoside hydrolase 61. Appl Environ Microbiol 2011, 77(19):7007-7015.

55. Couturier M, Navarro D, Olive C, Chevret D, Haon M, Favel A, LesageMeessen L, Henrissat B, Coutinho P, Berrin J-G: Post-genomic analyses of fungal lignocellulosic biomass degradation reveal the unexpected potential of the plant pathogen Ustilago maydis. BMC Genomics 2012, 13(1):57.

56. Fungal Genetics Stock Center. http://www.fgsc.net/.

57. Penman D, Britton G, Hardwick K, Collin HA, Isaac S: Chitin as a measure of biomass of Crinipellis perniciosa, causal agent of witches' broom disease of Theobroma cacao. Mycol Res 2000, 104(6):671-675.

58. Blakeney AB, Harris PJ, Henry RJ, Stone BA: A simple and rapid preparation of alditol acetates for monosaccharide analysis. Carbohydr Res 1983, 113(2):291-299.

59. Mort AJ, Parker S, Kuo MS: Recovery of methylated saccharides from methylation reaction mixtures using Sep-Pak C18 cartridges. Anal Biochem 1983, 133(2):380-384.

60. Naran R, Pierce ML, Mort AJ: Detection and identification of rhamnogalacturonan lyase activity in intercellular spaces of expanding cotton cotyledons. The Plant Journal 2007, 50(1):95-107.

61. Sumner JB, Graham Wtao VA: Dinitrosalicylic acid: a reagent for the estimation of sugar in normal and diabetic urine. J Biol Chem 1921, 47(1):5-9.

62. Miller GL: Use of dinitrosalicylic acid reagent for determination of reducing sugar. Anal Chem 1959, 31(3):426-428.

63. Squina FM, Mort AJ, Decker SR, Prade RA: Xylan decomposition by Aspergillus clavatus endo-xylanase. Protein Expr Purif 2009, 68(1):65-71.

64. Martin FC: A rapid and sensitive method for the analysis of carbohydrate components in glycoproteins using gas-liquid chromatography. Anal Biochem 1982, 123(2):336-341.

65. Komalavilas P, Mort AJ: The acetylation of O-3 of galacturonic acid in the rhamnose-rich portion of pectins. Carbohydr Res 1989, 189:261-272.

66. Sorghum Genome Database. http://www.phytozome.net/sorghum.

67. Keller A, Nesvizhskii Al, Kolker E, Aebersold R: Empirical statistical model to estimate the accuracy of peptide identifications made by MS/MS and database search. Anal Chem 2002, 74(20):5383-5392.

68. Old WM, Meyer-Arendt K, Aveline-Wolf L, Pierce KG, Mendoza A, Sevinsky JR, Resing KA, Ahn NG: Comparison of label-free methods for quantifying human proteins by shotgun proteomics. Molecular \& Cellular Proteomics 2005, 4(10):1487-1502.

69. SignalP software. http://www.cbs.dtu.dk/services/SignalP/.

70. Bendtsen JD, Nielsen H, von Heijne G, Brunak S: Improved prediction of signal peptides: SignalP 3.0. J Mol Biol 2004, 340(4):783-795.

doi:10.1186/1754-6834-5-52

Cite this article as: Saykhedkar et al:: A time course analysis of the extracellular proteome of Aspergillus nidulans

growing on sorghum stover. Biotechnology for Biofuels 2012 5:52.

\section{Submit your next manuscript to BioMed Central and take full advantage of:}

- Convenient online submission

- Thorough peer review

- No space constraints or color figure charges

- Immediate publication on acceptance

- Inclusion in PubMed, CAS, Scopus and Google Scholar

- Research which is freely available for redistribution 